Article

\title{
The Effects of Capital and Energy Subsidies on the Optimal Design of Microgrid Systems
}

\author{
Pablo Benalcazar ${ }^{1, *(1)}$, Adam Suski ${ }^{2, *}$ and Jacek Kamiński ${ }^{1, *(1)}$ \\ 1 Division of Energy Economics, Department of Policy and Strategic Research, Mineral and Energy Economy \\ Research Institute of the Polish Academy of Sciences, 31-261 Krakow, Poland \\ 2 Department of Management Engineering, Technical University of Denmark, 2800 Kongens Lyngby, Denmark \\ * Correspondence: benalcazar@min-pan.krakow.pl (P.B.); adam.suski@outlook.com (A.S.); \\ kaminski@min-pan.krakow.pl (J.K.)
}

Received: 9 January 2020; Accepted: 17 February 2020; Published: 20 February 2020

\begin{abstract}
Microgrids constitute an attractive solution for the electrification of areas where grid extension is not technically feasible or prohibitively expensive. In recent years, national governments have implemented various support policies to encourage the deployment of renewable energy systems (RES) and microgrid hybrid-powered systems. A fundamental aspect during the design and disposition of these types of units is the determination of the optimal configuration and sizing of each power generation component. Furthermore, the optimal design of microgrids is strongly dependent on technological parameters, local meteorological conditions, among other factors. In this context, this paper investigates the effects of different policy measures on the optimal configuration of microgrids functioning in islanded mode. A computable model is employed to carry out a set of sensitivity analyses and assess the impact of capital and fuel subsidies on the levelized cost of electricity of various systems. The model employed for this study minimizes the total life cycle costs (TLCC) over the 20-year lifetime of the microgrid project. Besides, as meteorological conditions are crucial parameters to consider while designing microgrids, a sensitivity analysis is conducted to examine the effect of wind speed and solar irradiation on the capacities of each distributed generation units. Our results indicate that capital subsidies, as well as fuel price variations, have a substantial effect on the final design of microgrid systems for rural electrification.
\end{abstract}

Keywords: microgrids; subsidies; optimization; financial incentives; policy instruments

\section{Introduction}

In the next decade, it is expected that the developing economies mainly located in sub-Saharan Africa, Central and Southern Asia, and South America will face significant challenges in achieving the ambitious goals of providing access to clean energy to all people and delivering universal access to electricity $[1,2]$. Despite the remarkable progress on the rural and urban electrification rates around the world $[3,4]$, and on the increasing number of innovative technologies suitable for off-grid applications, there are various factors that have hampered the success of national and local electrification projects, namely infrastructure, technical, economic, market, policy, and regulatory barriers [5-7].

In recent years, these issues have been at the forefront of the debate of clean energy, inequality, poverty, and climate change and have attracted the attention of intergovernmental organizations, policymakers, and other key stakeholders [8]. This has led to the adoption of various global action plans and, in some cases, legally binding agreements that provide blueprints to address the future challenges for sustainable development $[9,10]$. A clear example of these types of action plans and perhaps one of the most important in the scope of this article is Goal \#7 of the United Nations Sustainable Development Goals (SDG7). SDG7 promotes investment in energy infrastructure and clean energy technologies as 
well as the expansion of infrastructure for supplying modern and sustainable energy services. In this context, national and local governments have also taken action by launching numerous programs aimed at increasing the electrification rates of small rural and isolated communities [11].

Over the past few years, the technological development of renewable energy sources (RES) and declining costs of batteries have enhanced the popularity of stand-alone off-grid power systems, in particular, distributed generation and microgrids. Microgrids combine multiple energy technologies within the scope of one system (usually small- or medium-sized systems), including RESs, conventional generators, and energy storage technologies. These types of systems have a strong potential for electrification projects since they are cost-competitive (when compared to the option power grid extension), they can reduce greenhouse gas emissions, and use locally available resources. Additionally, the hybridization of renewable energy sources with small conventional units can provide high reliability by enhancing the resilience of the system to severe weather conditions and the technical benefit of being flexible to adapt to the requirements of the local communities [12]. Therefore, several studies have focused on estimating the future economics of microgrids including their levelized cost of electricity (LCOE). IRENA [13] projects that by the year 2035, the LCOE will drop to $\$ 0.2 / \mathrm{kWh}$ for projects with approximately $90 \%$ of renewable fraction, as shown in Figure 1.

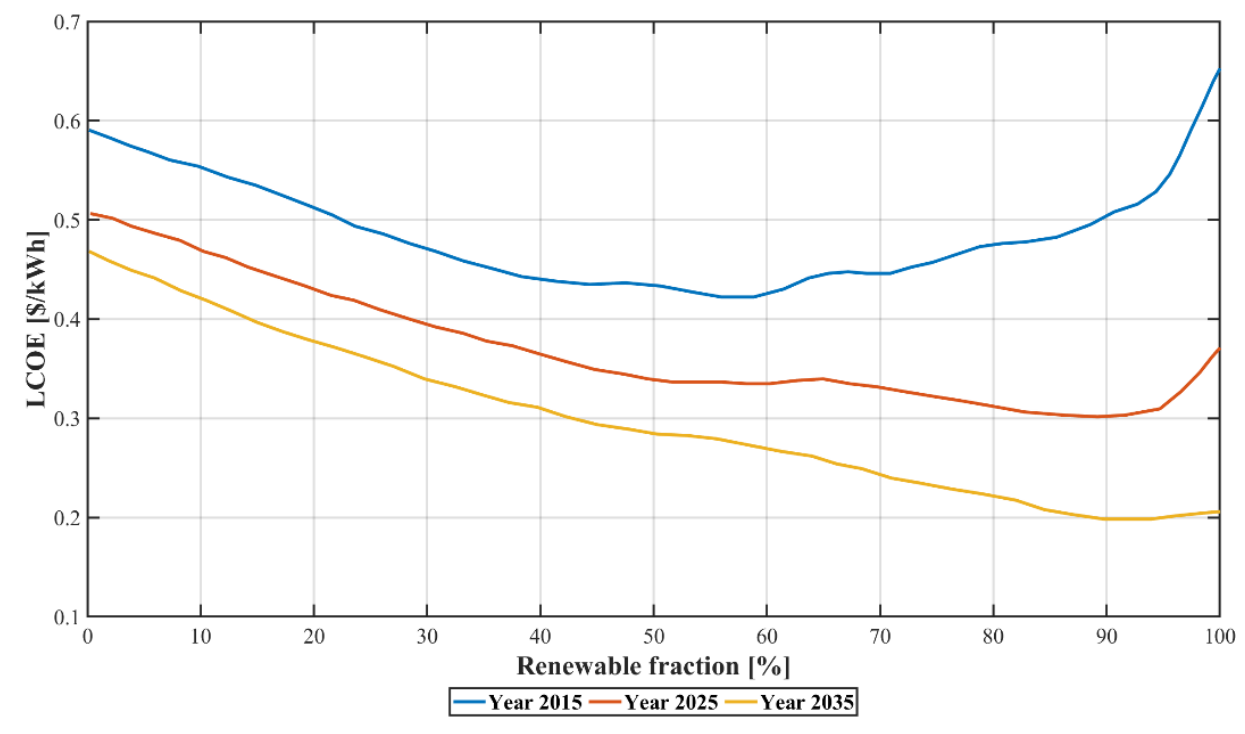

Figure 1. Renewable fraction vs. real levelized cost of energy for 2015, 2025, and 2035 [13].

Yet, despite the significant benefits that microgrids offer, their widespread deployment in rural electrification applications has been relatively slow due to their complicated financial and technical structure, including their high upfront costs, significant financial risks, and intricate business models [14]. Thus, in developing regions, it is common to find technical and financial support mechanisms offered by national and local governments or public-private partnerships. The available mechanisms vary significantly depending on the financial structure of the project, the region, and the technological priorities of the microgrid system; however, it is clear that in the last couple of years, support mechanisms such as these have had an important impact on the diffusion rates of microgrid systems and in their social acceptance. In addition, national governments have also implemented numerous policy interventions for their microgrid electrification projects, including subsidies, tax incentives, financial support, and concessions [15]. A current example of the large-scale application of these policy interventions and financial support mechanisms is the 'Nigeria Electrification Project' [16]. The aim of the project, which is funded by the World Bank, is to deploy hybrid mini- and microgrids to approximately one million Nigerian households and micro, small, and medium enterprises (MSMEs). To achieve this goal, the project consists of four components and the combination of two different support mechanisms: subsidies and performance-based grants. One of the subcomponents is done 
through a tendering procedure of grant subsidies for microgrids in preselected locations. Moreover, the subsidy is awarded based on several eligibility criteria and depending on the number of connections. In the United Republic of Tanzania, the local Rural Electrification Agency provided financial support to the use of microgrids by using matching grants, where the agency matched the community or private financial contribution to the project at 1:1 match [17]. In addition to the governmental support, performance grants and long-term loans were employed, where the former was based on the quality of service, while the latter included low long-term interest rates. In 2016, the Ministry of New and Renewable Energy (MNRE) of India launched the 'Off-grid and Decentralized Solar Applications Programme' [18]. The objective was to provide financial assistance to remote solar installations. Capital subsidies of up to $90 \%$ were offered depending on the intended use of the project, type of stakeholders involved, and installed capacity. In the same year, the Government of Indonesia developed a set of regulations with the ambitious target of electrifying the remaining isolated areas of the country (nearly 15\% of its population) with the use of off-grid solutions $[19,20]$. The "Indonesia Terang" (Bright Indonesia) program, which was introduced with the adoption of a special ministerial decree, was expected to enhance the electrification rate in rural areas through the investment and development of microgrids. Unfortunately, the program has experienced several delays due to the lack of funds and lack of local agreements. In Cambodia, the Rural Electrification Fund provided incentives for investments in microgrids in the form of grants, tariff subsidies, and zero interest rate loans [21,22]. The level and type of support depended on various eligibility criteria, including the type of technology used, location, and economic indicators.

The increasing interest in the use of microgrids as a source of clean and affordable energy has also prompted researchers to develop novel techniques and decision support tools in the areas of sizing and optimization. The process of finding the optimum capacity and generation schedule of microgrids is a complex procedure that can involve a large number of technical and economic variables. Furthermore, depending on the scale and primary goal of the microgrid project, different aspects need to be considered during the development of the optimization framework, including technical, economic, financial, political, geographical, environmental, and social aspects. Moreover, the variability and unpredictability of weather resources like solar irradiation and wind speed introduce a number of uncertainties that pose a series of challenges in the optimization process. To overcome the abovementioned challenges, researchers have developed a number of solutions that can be employed for the feasibility study of microgrids and hybrid-powered systems. Among the most common approaches employed for the development of microgrid management solutions are genetic algorithms and linear or mixed-integer linear programming models. For instance, in [23] the authors employed a genetic algorithm to optimize the component size of a hybrid renewable energy system comprised of photovoltaic panels, a backup generator, and a battery, while minimizing the cost of energy (COE). The authors of [24] developed a linear programming (LP) model to minimize the production costs of electricity in an autonomous renewable power system. In [25] a MILP approach was proposed to find the optimal operating schedule of a microgrid while considering penalties for task interruptions. In [26] the authors used an LP method to optimize a residential energy system with the goal of minimizing $\mathrm{CO}_{2}$ emissions. The authors of [27] developed a model based on a genetic algorithm (GA) approach to minimize the annualized costs of the system considering the loss of power supply probability. Reviews of research works related to sizing and optimization of microgrids can be found in [28-30].

Although there is a wide range of methods, algorithms, and decision-support tools for sizing and optimization of microgrids, an important gap in the literature exists with respect to the impacts of capital and energy subsidies on the optimal design of microgrids. In this context, this study tries to fill this gap by providing a quantitative analysis of the effects of these support instruments with the application of an optimization-based decision support tool. Moreover, this study focuses on assessing the effects of subsidies for green technologies on the LCOE. The model employed in this research minimizes the total life cycle costs (TLCC) of a microgrid system over its expected lifetime. In addition, this study presents the effects of meteorological conditions on the optimal architecture of microgrids. 
This paper is organized as follows. Section 2 provides a summary of the relevant literature regarding the impacts of different policy measures on the design of microgrid systems. Section 3 contains the problem definition. In Section 4 the optimization framework employed in the study is described. Section 5 presents the illustrative example and the sensitivity parameters. Section 6 examines the results of the sensitivity analyses. Section 7 discusses the policy implications and concludes the paper.

\section{Literature Review}

Despite the increasing number of microgrid projects for off-grid electrification, there are a limited number of studies that have assessed the effects of policy measures on the design of microgrid systems. Most of the literature available has primarily focused on specific case studies that demonstrate the technical feasibility of a project or on demonstrating the advantages of the proposed optimization method. Often, because of numerous simplifications, microgrid studies have concentrated on finding new solutions to technological and operational challenges and have ignored the impact of different political and social barriers as well as their policy implications. A simplified diagram that depicts the microgrid barriers to entry and their relationship is presented in Figure 2.

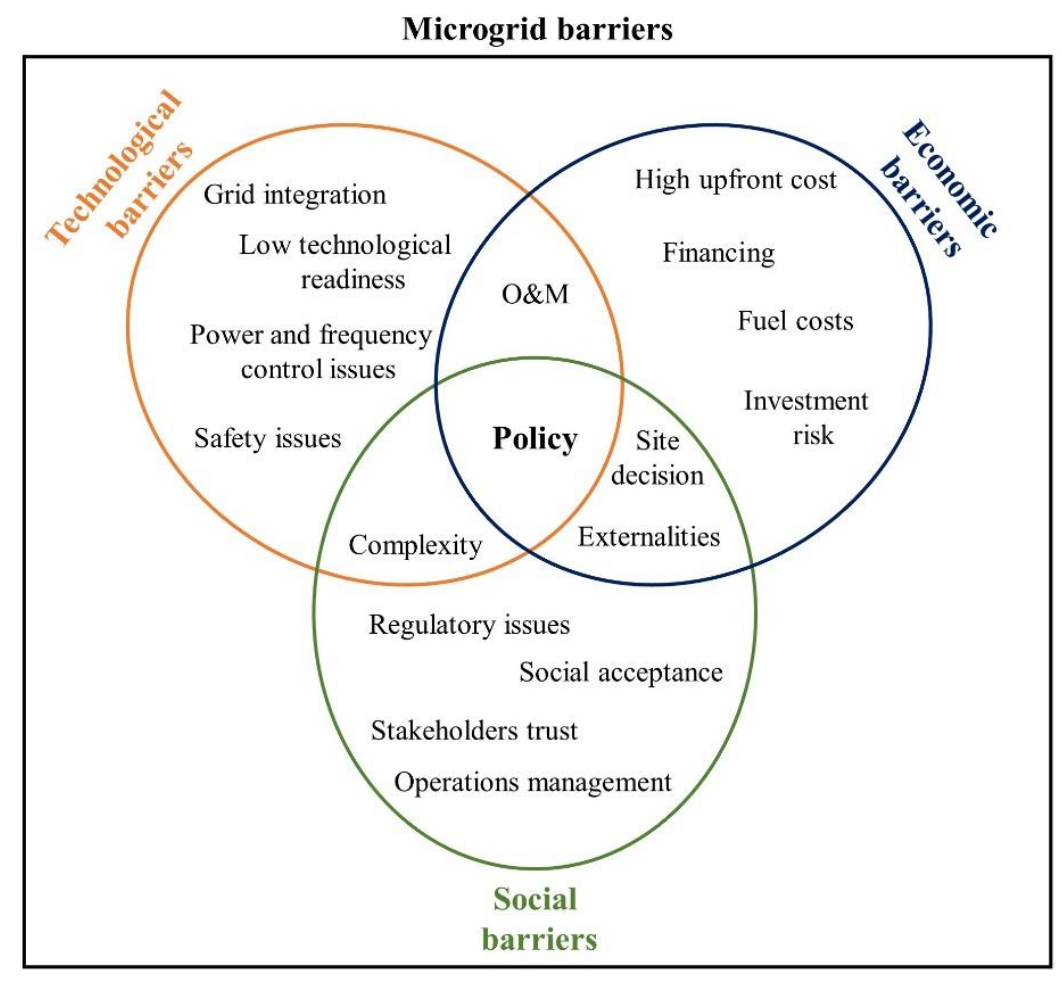

Figure 2. Microgrid deployment barriers [5].

A major barrier that has affected the adoption of microgrids for off-grid electrification in developing countries has been the high upfront capital costs. Consequently, governments have often employed incentives to promote the development of microgrids.

As it was mentioned earlier, only a small number of studies have examined the effects of policies and financial mechanisms on the optimal design of microgrids, and just a fraction of them have utilized computer-based mathematical models. [6] employed the distributed energy resources customer adoption model (DER-CAM), a microgrid analysis tool for optimal sizing and dispatch management, to study the business model of three types of microgrids. Based on the results of their simulations, several policy recommendations for microgrid investments were presented. In [31] the authors used a novel method based on an evolutionary game model integrated with real options to estimate the energy storage subsidies for microgrids. The study suggested that energy storage subsidies combined 
with initial cost subsidies may play an important role in the diffusion of microgrid systems. The authors of [14] studied the role that government subsidies play on the operational efficiency of the microgrid industry chain. The authors developed a model based on game theory to investigate different subsidy strategies and market participants (e.g., government, investor, equipment supplier, operator, and user). Moreover, the study proposed different subsidy practices to promote investments in microgrid projects. In [32] a multi-stage incentive model was used to investigate different cooperative and incentive mechanisms for microgrid investments. The study assessed the crucial factors influencing the investment and development of microgrid projects. In [33] the authors developed a novel microgrid design tool, called microgrid decision support tool (MDSTool) to find the optimal size and operation of a microgrid system planned for a university campus. The study considered several incentive policies. Their findings showed that renewable energy incentives, tax reductions, and grid services have a significant impact on the financial feasibility of such systems and on the main economic and technical indicators of the microgrid. In a later study, the authors of [34] used the MDSTool to evaluate the effects of different policy measures on the optimal deployment of a microgrid in California. The objective function of the model maximized the profit of the project over the 25-year expected lifetime of the system. The issue of policy uncertainty was considered in their study with an extensive sensitivity analysis. The results from the simulation showed that incentives and tax credits have a substantial effect not only on the system profitability but also on the final microgrid configuration.

Among all the incentives available to promote the development of microgrids, the effects of feed-in-tariffs (FiT) have been the mostly discussed in the literature. In [35] the DER-CAM model was employed to determine the optimal operation of battery storage in new and existing residential PV systems benefitting from FiT incentives. Several FiT schemes and battery storage capacities were considered in the sensitivity analysis. Their investigation demonstrated the substantial value that energy storage units with PV arrays have on the revenue streams of systems under FiT incentives. The authors of [36] also looked at the effects of FiT as well as capital grants incentives on the cost-effectiveness and financial viability of microgrid projects. The analysis was conducted from the perspective of different individual stakeholders, precisely governments, energy consumers, and energy hub operators. Their findings showed that from a government perspective, it is more cost-efficient to incentivize a combination of capital grants and FiT than only FiT programs. In [37] the authors demonstrated the application of a harmony search algorithm for the optimal operation of a 17-bus low voltage grid-tied microgrid, comprised of two distributed energy resources with a PV array, a wind turbine, a fuel cell, and hydrogen storage. In their study, one of the research scenarios examined the introduction of a subsidy tariff policy. This type of subsidy proved to be essential to make the system financially effective and the considered technologies viable. In [38] a leader-follower Stackelberg game approach was used to investigate the effects FiT and emission trading policies on the investment decision of a solar photovoltaic-powered community microgrid (SPCM). The case study focused on China and demonstrated that in some specific cases governmental policies such as FiT and certified emission reductions may induce the development of SPMC.

Finally, several studies have provided comprehensive reviews of various policy mechanisms related to the development of microgrid investment projects. In [39] the authors presented a systematic review of the current advantages, barriers, and subsidy support schemes of microgrid systems. The mechanisms reviewed comprised capital subsidies, tax reductions, climate, carbon taxes, and financing services. In [40] the most important aspects of microgrid development in the United States was reviewed. It summarized the various financial incentives and subsidy policies available for microgrid systems at the local and federal level. The authors of [41] gathered and evaluated numerous policies related to microgrid project implementations around the world. Moreover, different examples of policies and regulations were discussed in detail. In [42] the authors reviewed the impact of governmental policy frameworks on the optimal design of microgrids with hybrid energy systems. The main focus of the study was to review the most recent methods available in the literature for the evaluation of several governmental policies. In addition, the authors discussed different policy interventions (e.g., financial 
incentives, carbon tax, minimum renewables) that have been considered in microgrid feasibility studies. In [5] the authors reported the recent perspectives, barriers, and policies for distributed energy sources in the European Union, United States, and China. Additionally, a comprehensive review of the governmental regulations affecting the deployment of microgrids in abovementioned countries was presented.

\section{Problem Definition}

To evaluate the impact of various subsidy policies on the optimal architecture of microgrids, we consider the case where a government or a non-governmental organization is interested in laying out a program to expand the electrification rates in a specific region within a country. From a series of consultations with key stakeholders, policymakers, and planners, two important barriers were identified that may impact the success of the program: high upfront costs and the technical complexity in sizing the different distributed generation units. Additionally, before any specific compromise is made on the type of subsidy or financial incentive that may be offered to participants in the program, policymakers decide to carry out an assessment on the potential consequences of different subsidies schemes on the LCOE, TLCC, $\mathrm{CO}_{2}$ emissions, and optimal configuration of the microgrid systems. From the assessment, decision-makers will be able to better understand the capacities, locations, and configurations of the systems with a clear perspective on the economic and technical feasibility of the projects.

\section{Method}

In this study, we employed a computable model to evaluate the potential effects of policy interventions, namely capital subsidies and fossil fuel subsidies on the optimal configuration of microgrids with hybrid power sources. Furthermore, to show the role that subsidies play on the economic viability, design, and disposition of these types of systems, an illustrative example is provided. The hybrid-microgrid example, which is based on several simplifying assumptions and values obtained from the literature, is intended to represent a generic case study from which policymakers and other stakeholders can widen their understanding of microgrid design. In our analysis, for simplicity, we excluded the representation of demand-side management (DSM) strategies and technologies (e.g., community involvement, limiting business hours, efficient appliances and lights, load limiters, smart controllers, prepaid meters, among others) since these practices frequently require detailed information on the local cultural context of the unelectrified community (including, household income, customer expectation, an microgrid business model). Moreover, the example demonstrates the impact that subsidy mechanisms - mainly designed to promote renewable energy technologies-have on the LCOE of these systems. The microgrid combines solar and wind generating units, a battery storage system, and a backup diesel generator. The schematic layout of the islanded system is shown in Figure 3.

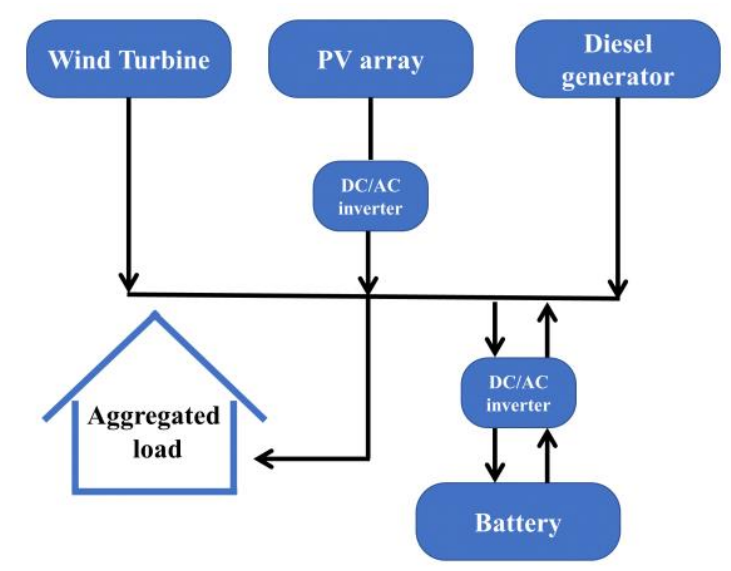

Figure 3. Schematic representation of the microgrid system. 
The decision support tool employed in this study is an improved and extended version of an optimization model developed at the Mineral and Energy Economy Research Institute of the Polish Academy of Sciences (MEERI PAS). The model was originally developed for the feasibility study of a microgrid system for rural electrification in a developing country and is mathematically formulated as a linear program. Furthermore, the linear programming approach used for the development of the decision support tool is a well-established method for pre-feasibility analyses since it is characterized by its simplicity, flexibility, and practical computational times [43]. Analogous to other microgrid decision support tools (e.g., HOMER and DER-CAM) the optimization model used in this study considers key technical, meteorological, and economic factors that have a major influence on the design and performance of microgrid projects for rural electrification. Additionally, the model is a generic tool that can be used to evaluate a variety of cases involving different power sources and meteorological conditions.

The objective function of the model minimizes the TLCC of the microgrid over its lifetime. Generally, the configuration with the lowest TLCC also leads to the minimization of the levelized cost of electricity, which is defined as the ratio of the TLCC to the total sum of the generated electricity during the operation of the system. The overall life cycle costs of the microgrid is calculated as the sum of the TLCCs of every component, including technology-specific capital costs, O\&M costs, fuel costs, and replacement costs.

The optimization of the TLCC is subject to economic and technical constraints of the distributed generation units. The considered constraints are related to:

- The sum of the individual loads within the microgrid must be always met by the sum of the energy produced by each technology and the energy discharged from the battery.

- The diesel generator output must be lower than its nameplate capacity (considering its efficiency).

- The relationship between intermittent renewables (meteorological conditions) and their capacities are represented in the model by capacity factors.

- The operation of the battery storage is limited by its charge/discharge rates and the depth of discharge.

The model estimates the required capacity of each component in the microgrid as well as their operating schedule at each hour of the time horizon. In the case of the battery storage, the model includes in the objective function a one-time replacement option which can occur within the project lifetime. The replacement cost of the subsystem is equivalent to the capital costs converted into a stream of equal annual payments with the use of the capital recovery factor. The optimization tool was implemented in GAMS (General Algebraic Modelling System) on an Intel i7-8650U (1.9 GHz personal computer with 8.0 GB of RAM, running a 64-bits Windows 10) and solved using CPLEX 12.9. The optimization framework described in this section was then applied to analyze the assumptions and data of the illustrative example. After running a series of sensitivity cases with different capital costs, fuel prices, interest rates, and meteorological parameters, the results were exported to Excel and then post-processed with MATLAB 2019b. The flowchart of the optimization framework is presented in Figure 4. 


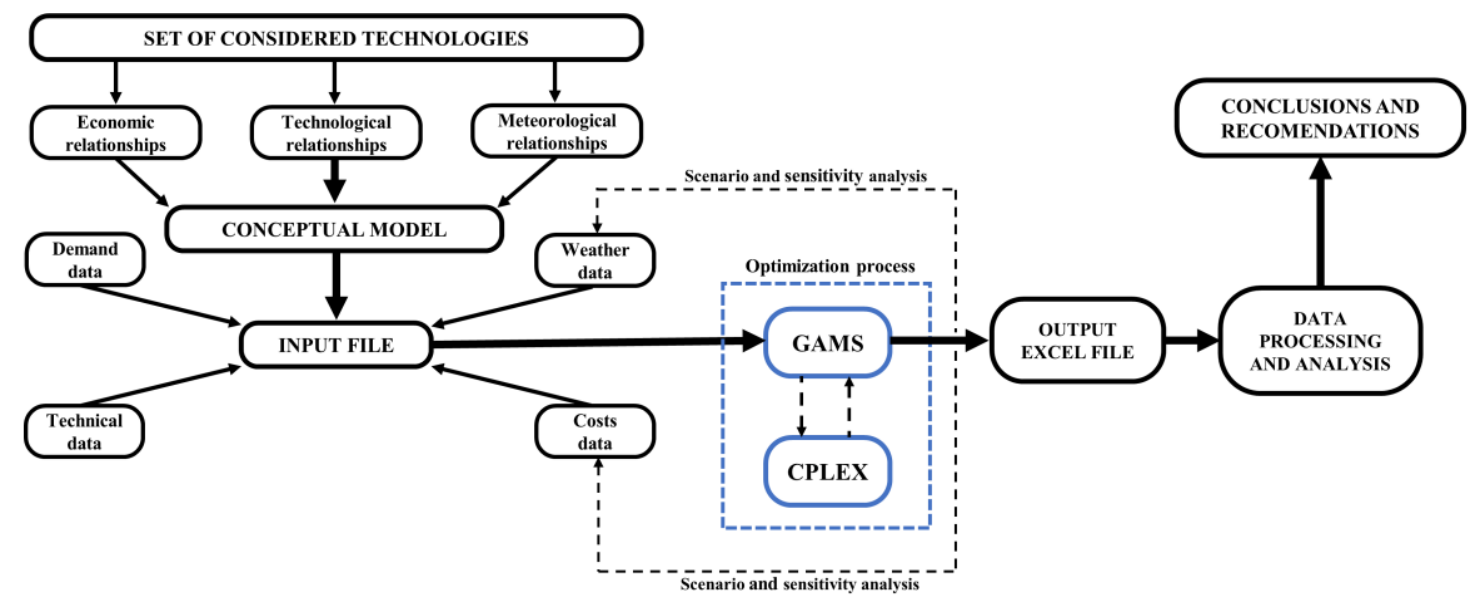

Figure 4. Flowchart of the optimization framework.

\section{Case Study and Sensitivity Parameters}

\subsection{Case Study}

Currently, the majority of the 840 million people who lack access to electricity are concentrated in rural areas of developing economies [44]. Sub-Saharan Africa, India, the Middle East, Asia, and other small regions located in tropical climate zones constitute over $90 \%$ of the areas without electricity access [4]. During the first part of the 21st century, significant progress was made in improving the access to reliable and affordable electricity in developing countries, mainly achieved by power line extensions or with the deployment of distributed fossil fuel generators. However, by 2030, it is expected that off-grid renewable solutions will play a critical role in accelerating the progress towards universal electricity access. Off-grid energy will comprise nearly $60 \%$ of the new electrification investments, with almost half of these investments in mini- and microgrids [45]. In this context, to examine the impact of different subsidy programs on the optimal architecture of microgrids, we consider the case of an unelectrified rural community located in a tropical climate zone. It should be stressed that certain areas located in tropical climates are characterized by a medium-high to high potential of solar, wind, and hydropower sources, which makes them attractive for the deployment of renewable-based microgrid systems [46]. However, some countries located in these areas continue to subsidize fossil fuels which often makes diesel-fired generators economically competitive, hindering the deployment of renewable technologies [47].

The technical and economic details of the illustrative example can be summarized into three main points:

- Meteorological site data: The site-specific meteorological hourly data (e.g., global horizontal irradiation (GHI) and wind speed) were obtained from the National Solar Radiation Data Base (NSRDB) [48], which is an open-access database created by National Renewable Energy Laboratory (NREL). The selected site was characterized by an average daily solar irradiation of $5.75 \mathrm{kWh} / \mathrm{m}^{2} /$ day and an average wind speed of $4.19 \mathrm{~m} / \mathrm{s}$. 
- Load profile: The load profile of a low-income rural village was generated with LoadProGen, a MATLAB tool capable of estimating the energy consumption of a household or the aggregation of households through a bottom-up approach [49]. The software tool has been specially designed to support off-grid systems. Moreover, LoadProGen takes into account various parameters related to the number of households, types and number of electrical appliances, appliance nominal output, functioning windows, functioning times. Furthermore, to generate a realistic load profile, different uncertainty parameters were also considered in the illustrative case (e.g., random variation of functioning time and windows). The load profile was devised for a village composed of 90 households (approximate load of $38,743 \mathrm{kWh} /$ year) and based on the electrical appliance usage habits of rural communities reported in [50,51].

- Techno-economic data: The assumptions and techno-economic data employed in the model are summarized in Table 1. Each technology considered in the microgrid system has its specific capital cost expressed in $\$ / \mathrm{kW}$, average yearly O\&M costs expressed as a percentage of capital costs, and expected lifetime. The data was gathered from various scientific publications and reports on feasibility studies of microgrid systems for rural electrification: in [52,53] for the PV array, in $[54,55]$ for the wind turbine, in $[52,56]$ for the diesel generator, and in $[57,58]$ for the electrical energy storage. The interest rate of $6 \%$ was selected after a careful investigation of lending rates in 107 developing economies, classified according to the economic groups of the United Nations Conference on Trade and Development (code 2160). In the fourth quarter of 2018, the median interest rate was $5 \%$ [59].

Table 1. Main technical and economic data of the considered system components.

\begin{tabular}{|c|c|c|c|c|}
\hline Technology & $\begin{array}{l}\text { Capital Costs } \\
(\$ / k W)(\$ / k W h \text { in } \\
\text { the Case of EES) }\end{array}$ & $\begin{array}{l}\text { O\&M Costs (\% of } \\
\text { Capital Costs) }\end{array}$ & Lifetime (Years) & Interest Rate (\%) \\
\hline PV array & 1200 & 1.5 & 20 & 6 \\
\hline Wind turbine & 2100 & 1.5 & 20 & 6 \\
\hline Diesel generator & 500 & 6 & 20 & 6 \\
\hline EES & 300 & 2 & 10 & 6 \\
\hline
\end{tabular}

\subsection{Sensitivity Analysis}

As it has been previously stated, there are a number of policy measures and subsidy schemes frequently employed by governments and other institutions to promote rural electrification with the use of microgrids. In this study, five different governmental interventions were considered: capital subsidies across all distributed generation technologies, capital subsidies for renewable technologies, capital subsidies for PV technologies, capital subsidies for wind technologies, and diesel price subsidies. These financial schemes are reflected in the simulations as a set of sensitivity analyses. In each case, the subsidies are represented as a percentage-wise reduction from a 'default capital cost' or 'default fuel price'. This is accomplished in the model by progressively reducing the values of the input parameters related to investment costs and diesel price by a percentage within the range of $5 \%$ to $95 \%$, at a $5 \%$ increase. Consequently, capital subsidies are represented in this study as a gradual reduction in the overall cost of installing a particular technology. A similar approach is adopted for the subsidization of fossil fuels. Additionally, to assess the impact of interest rate changes, a sensitivity analysis was conducted by varying the rate of interest from $1 \%$ to $18 \%$, at a $1 \%$ increase (without any policy instrument implemented). For the cases involving capital costs, fuel price subsidies, and interest rates, only one parameter was varied at the time, while the others were kept at default values. However, for the case where meteorological inputs were selected as sensitivity parameters, two parameters were varied simultaneously, resulting in multiple examples of different weather conditions. To generate the necessary data for the sensitivity analysis of different weather conditions, the baseline meteorological values (original one-year time series, hourly wind speed, 
and solar irradiance) were scaled by multiplying each hourly value by a constant factor. The factors were determined as the ratio of the desired annual average to the original average value. This is similar to the approach taken in [60] and in various feasibility studies [61,62]. The sensitivity parameters and their discrete values are presented in Table 2.

Table 2. Parameter variation for sensitivity analyses.

\begin{tabular}{|c|c|c|c|}
\hline Policy Instrument. & Sensitivity Parameter & Unit & Values \\
\hline $\begin{array}{l}\text { Subsidies across all } \\
\text { DG technologies }\end{array}$ & Capital costs of all technologies & $\%$ & 0-95 \\
\hline $\begin{array}{l}\text { Subsidies for renewable } \\
\text { energy technologies }\end{array}$ & $\begin{array}{l}\text { Capital costs of } \\
\text { renewable technologies }\end{array}$ & $\%$ & 0-95 \\
\hline Subsidies for PV technologies & Capital costs of PV technologies & $\%$ & 0-95 \\
\hline Subsidies for wind technologies & $\begin{array}{c}\text { Capital costs of } \\
\text { wind technologies }\end{array}$ & $\%$ & 0-95 \\
\hline Fossil fuel subsidies & Diesel price & $\%$ & 0-95 \\
\hline $\begin{array}{l}50 \% \text { subsidy for PV and energy } \\
\text { storage technologies }\end{array}$ & $\begin{array}{c}\text { Annual average wind speed } \\
\text { Annual average solar irradiation }\end{array}$ & $\begin{array}{c}\mathrm{m} / \mathrm{s} \\
\mathrm{Wh} / \mathrm{m}^{2} / \text { day }\end{array}$ & $\begin{array}{c}3-7 \\
2000-6000\end{array}$ \\
\hline None & Interest rate & $\%$ & $1-18$ \\
\hline
\end{tabular}

\section{Computational Results}

This section presents a summary of the findings obtained from the sensitivity analyses. The main objective is to provide a quantitative understanding of how policy interventions like capital and fossil fuel subsidies affect the LCOE, total $\mathrm{CO}_{2}$ emissions, total subsidy cost, and optimal configuration of microgrids for rural electrification.

\subsection{Subsidies across All Distributed Generation Technologies}

A common approach to financially support microgrids is the use of capital subsidies-although it has been widely discussed that they are not the most efficient way of incentivizing electrification projects (from a fiscal and financial standpoint) $[15,63]$. The level of this financial support varies depending on the location of the project, the type of technologies selected, among other crucial factors. Figures 5 and 6 show the optimal configuration of a microgrid with its corresponding TLCC and LCOE depending on the extent of subsidization. Figure 7 illustrates the total subsidy cost and total estimated $\mathrm{CO}_{2}$ emissions within the project lifetime. The reduction of the capital costs is applied to all the technological components of the system, which is shown in the figures by the gradual change in subsidy levels. In general, this financial support positively affects the deployment of solar and electrical energy storage technologies. The capacities of both technologies increase at a comparable rate. Furthermore, as the share of PV modules and battery storage increase (to meet the demand at all times), the role of the backup diesel generator decreases, which is represented by the downward trend in the diesel generator capacity and total $\mathrm{CO}_{2}$ emissions. The LCOE and TLCC decrease linearly with the progressive reduction in capital costs. When the microgrid project benefits from a $30 \%$ capital subsidy, the LCOE is approximately $\$ 0.20 / \mathrm{MWh}$. This value subsequently decreases by $\$ 0.01 / \mathrm{kWh}$ with each additional $5 \%$ reduction in capital costs. 


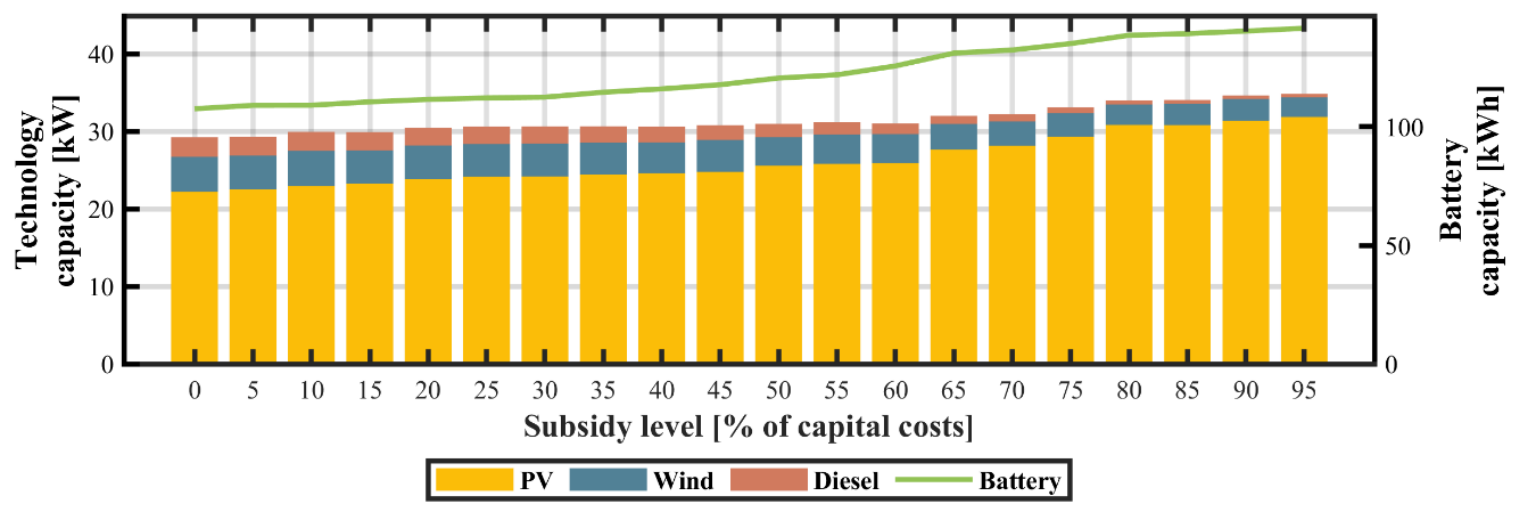

Figure 5. Simulation results of capital subsidies across all DG technologies. Impact on the capacity of DG technologies.

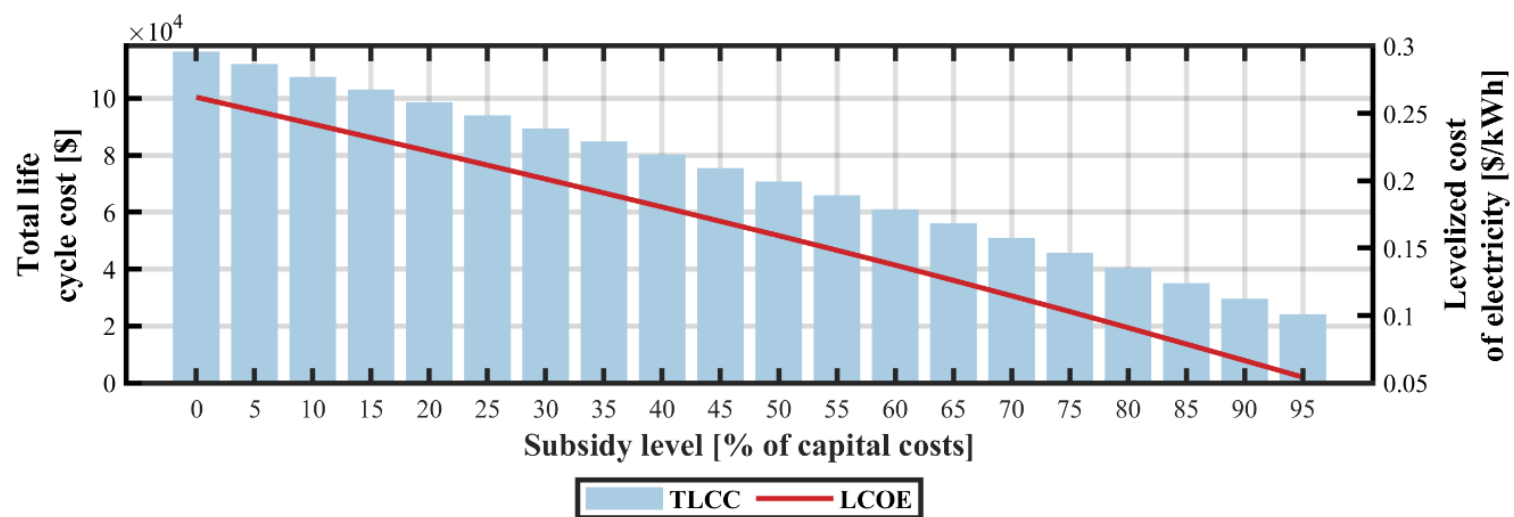

Figure 6. Simulation results of capital subsidies across all DG technologies. Impact on levelized cost of electricity (LCOE) and total life cycle costs (TLCC).

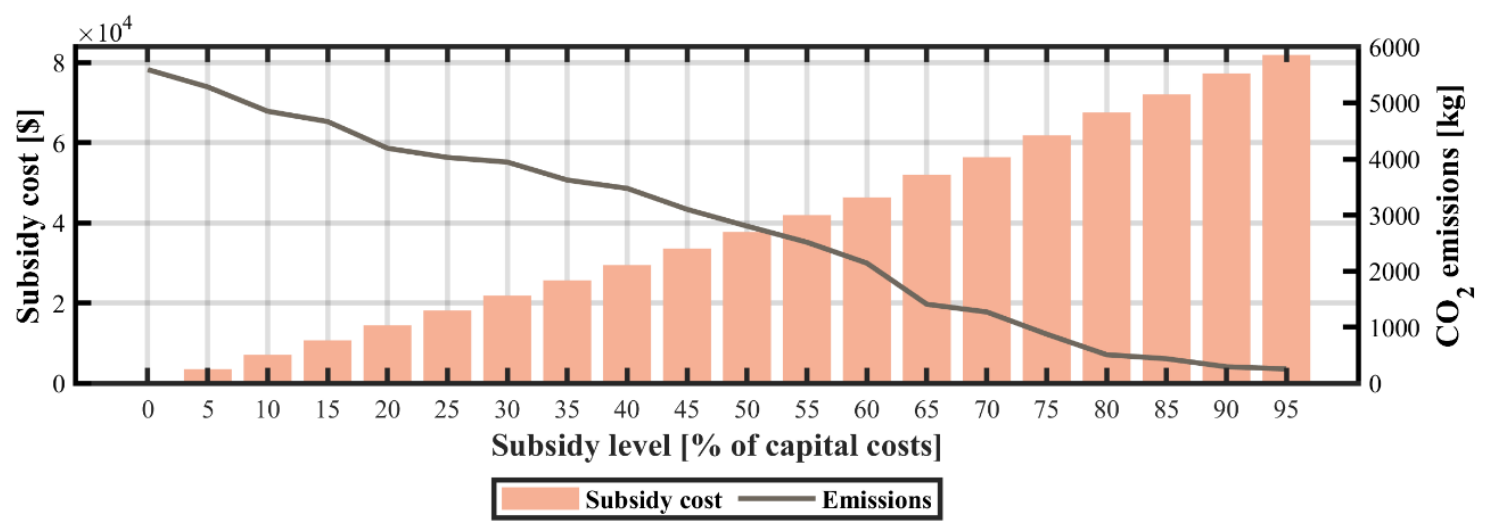

Figure 7. Simulation results of capital subsidies across all DG technologies. Impact on subsidy costs and $\mathrm{CO}_{2}$ emission levels.

\subsection{Subsidies for Renewable Energy Technologies}

In recent years, a sharp downward trend in the costs of renewable energy technologies has been observed. This has facilitated the uptake of renewables in microgrid energy systems. PV investment costs have fallen over $74 \%$ since 2009 , while onshore wind turbines costs have dropped by $22 \%$ in the same period [64]. This downward trend and the adoption of appropriate policy measures for off-grid energy systems may have a significant impact on the future profitability of microgrids as well as on their level of diffusion. Figures 8-10 illustrate the effects of capital subsidies offered only to PV and wind energy technologies on the optimal architecture of microgrids and other key variables. 
The capacity of wind technologies increases substantially in the absence of capital subsidies for EES. The need for storage decreases since wind energy tends to be distributed over the day, reflected Figure 8 by the reduction in battery capacity. It is worth noting that up to a $45 \%$ subsidy support, the capacity of the backup generator remains relatively unchanged while the capacities of the PV and wind energy technologies slightly increase. As the wind turbine production volume increases, to address the intermittent nature of wind power, the capacity of the diesel-powered backup generator increases, resulting in higher levels of $\mathrm{CO}_{2}$ emissions. The LCOE of a microgrid benefitting from capital subsidies for renewable energy technologies ranges from $\$ 0.21 / \mathrm{kWh}$ (at a 50\% subsidy) to $\$ 0.13 / \mathrm{kWh}$ (at a $95 \%$ subsidy).

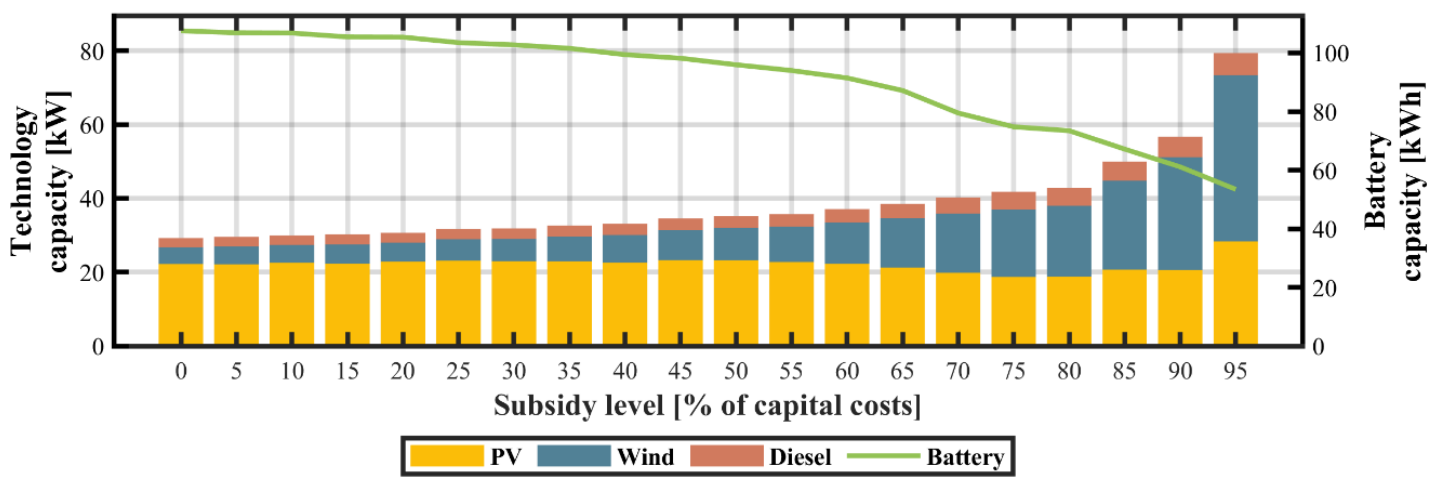

Figure 8. Simulation results of capital subsidies for renewable energy technologies. Impact on the capacity of DG technologies.

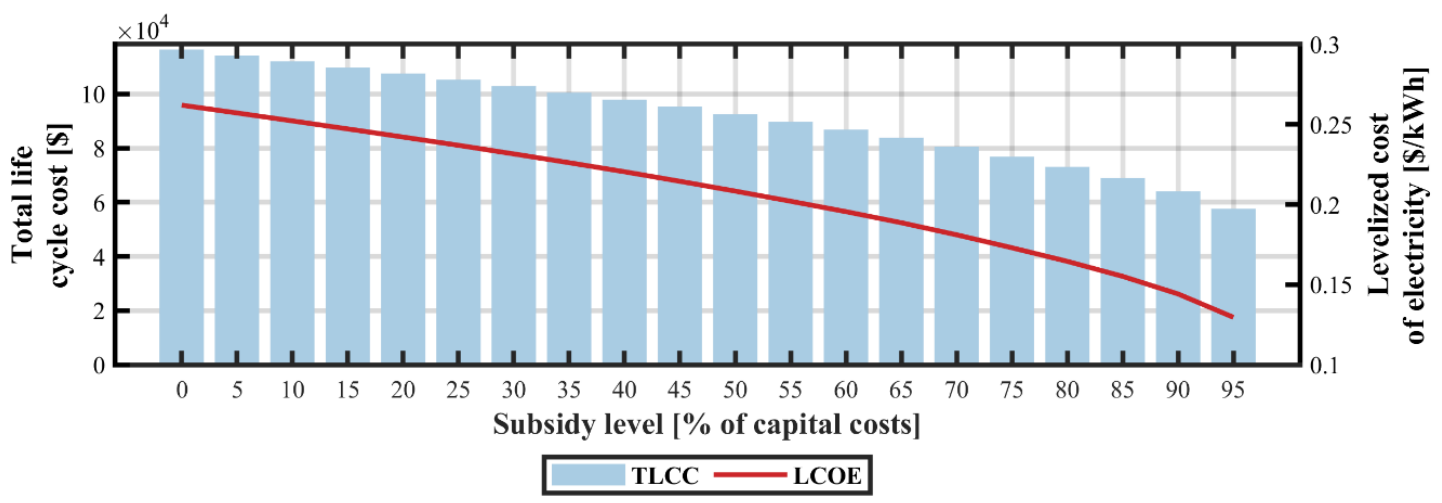

Figure 9. Simulation results of capital subsidies for renewable energy technologies. Impact on LCOE and TLCC.

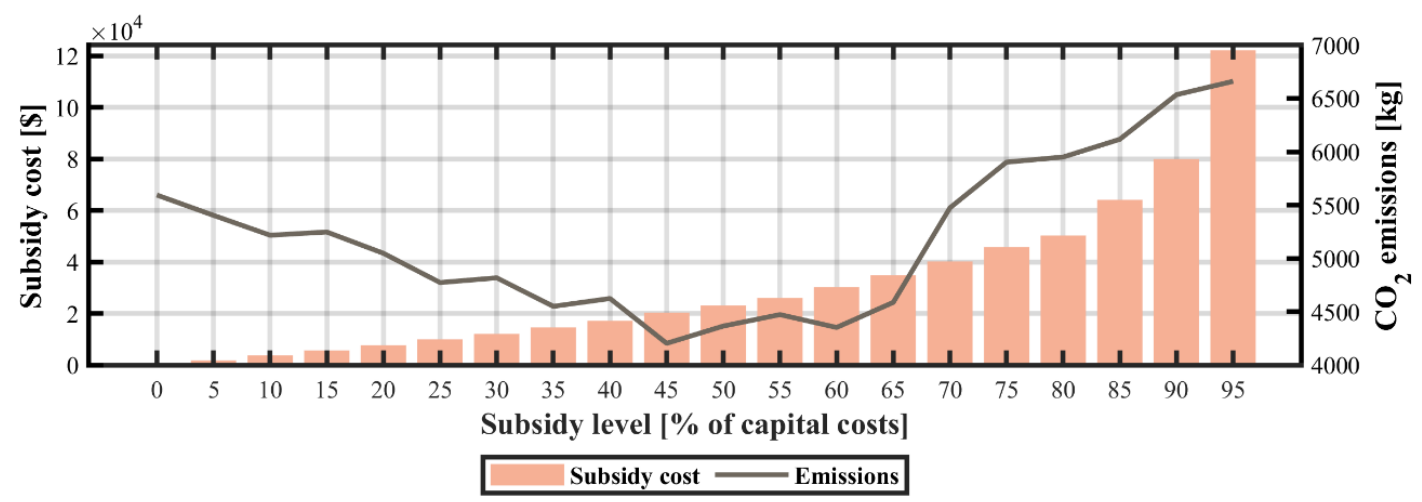

Figure 10. Simulation results of capital subsidies for renewable energy technologies. Impact on subsidy costs and $\mathrm{CO}_{2}$ emission levels. 


\subsection{Subsidies for PV Technologies}

The dramatic drop in PV module prices has led to the growing popularity of mini- and microgrid systems. Unfortunately, in several developing economies the high upfront costs and long payback periods of distributed PV pose a major barrier to their widespread deployment. Therefore, a common strategy employed by governments to reduce the capital costs of such technologies has been to provide financial incentives and subsidy schemes [65]. The results of the sensitivity analysis of capital subsidies for PV technologies are shown in Figures 11-13. The progressive increase in capital subsidies for PV technologies causes the model to displace wind and diesel subsystems, leading to a decrease in $\mathrm{CO}_{2}$ emission levels. At a $60 \%$ reduction in capital costs, the installed capacity of PV, and wind subsystems account for approximately $90.1 \%$ and $4.1 \%$, correspondingly. The LCOE is approximately $\$ 0.21 / \mathrm{kWh}$ and the TLCC of the system is $\$ 93,805$. The system configuration comprises a $2.17 \mathrm{~kW}$ diesel generator, a $33.5 \mathrm{~kW}$ photovoltaic subsystem, a $1.51 \mathrm{~kW}$ wind turbine, and a $114 \mathrm{kWh}$ battery. Above the subsidy level of 70\%, the microgrid is solely powered by PV in conjunction with batteries and a diesel backup generator.

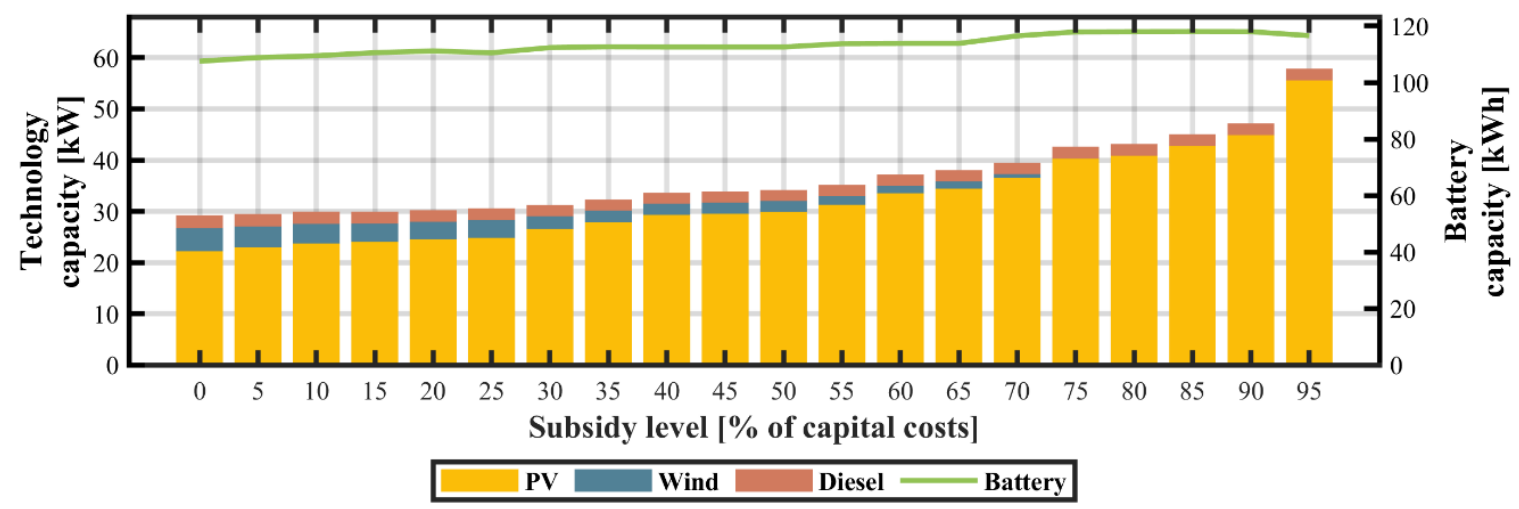

Figure 11. Simulation results of capital subsidies for PV technologies. Impact on the capacity of DG technologies.

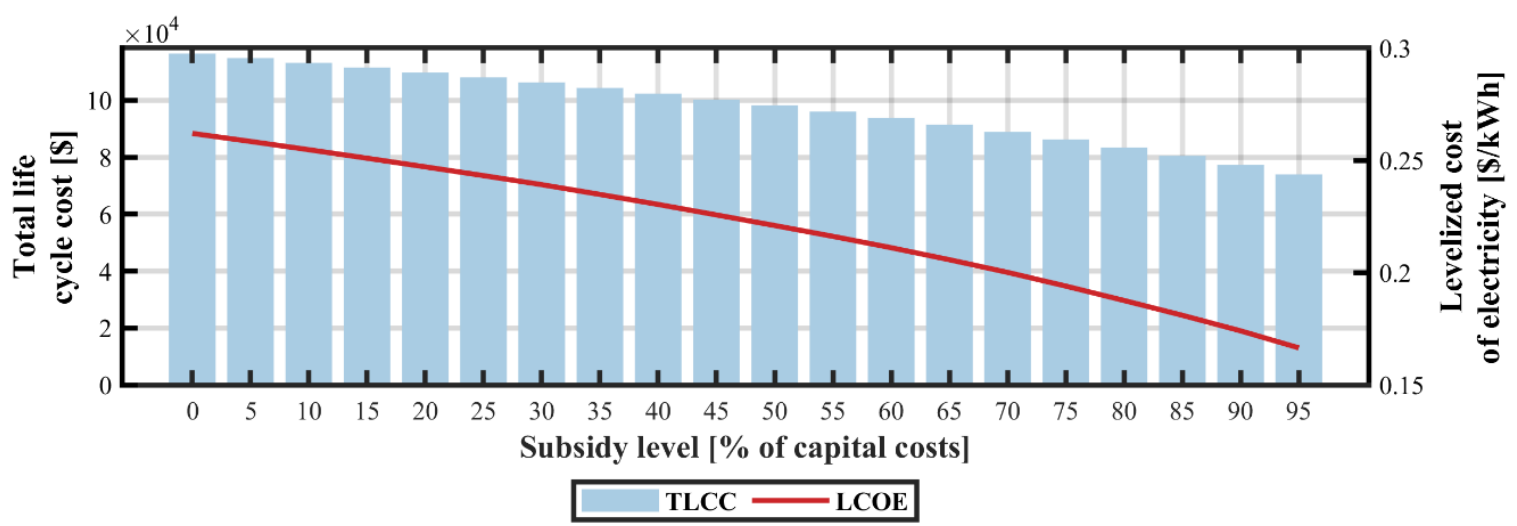

Figure 12. Simulation results of capital subsidies for PV technologies. Impact on LCOE and TLCC. 


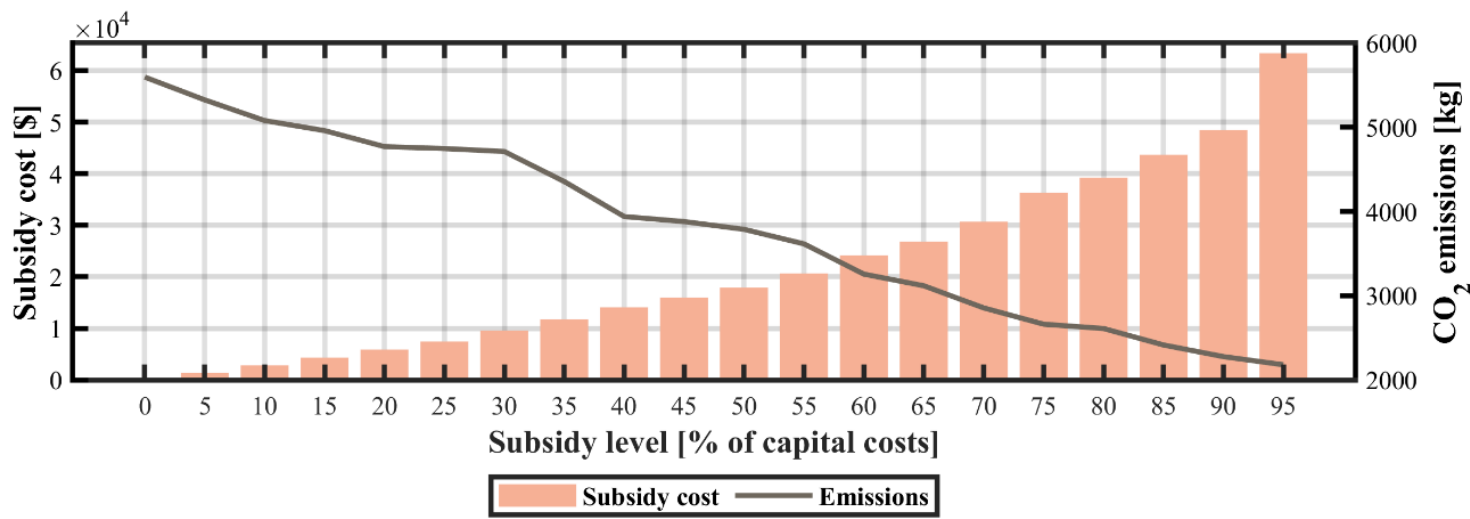

Figure 13. Simulation results of capital subsidies for PV technologies. Impact on subsidy costs and $\mathrm{CO}_{2}$ emission levels.

\subsection{Subsidies for Wind Technologies}

Similar to the current trend of solar PV module prices, a downward trend in wind turbine investment costs has been observed over recent years. Nonetheless, there is still the need for significant policy steps to promote the use of small wind turbines in microgrids [66]. Figures 14-16 present the results of the sensitivity analysis of the progressive reduction in capital costs of wind technologies. Subsidies for wind power show the highest levels of subsidy costs of all reported cases, mainly due to the high upfront capital costs of wind power. With a capital subsidy of $60 \%$, the capacity of the wind subsystem in the microgrid increases by over $400 \%$ (from 4.49 to $19.84 \mathrm{~kW}$ ). Furthermore, it accounts for nearly $53 \%$ of the total annual electricity generated and leads to an LCOE of $\$ 0.23 / \mathrm{kWh}$. As in other cases in which the capacity of wind power increases, subsidies for wind technologies lead to a rise in diesel capacity, resulting in a dramatic growth of $\mathrm{CO}_{2}$ emissions.

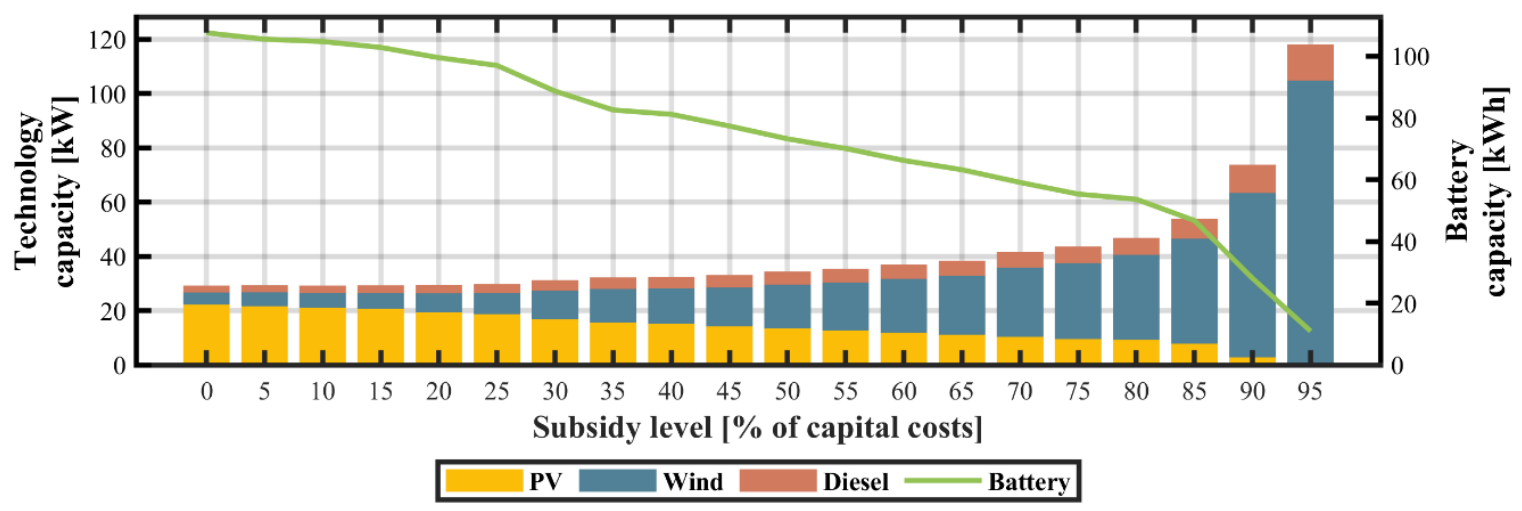

Figure 14. Simulation results of capital subsidies for wind technologies. Impact on the capacity of DG technologies. 


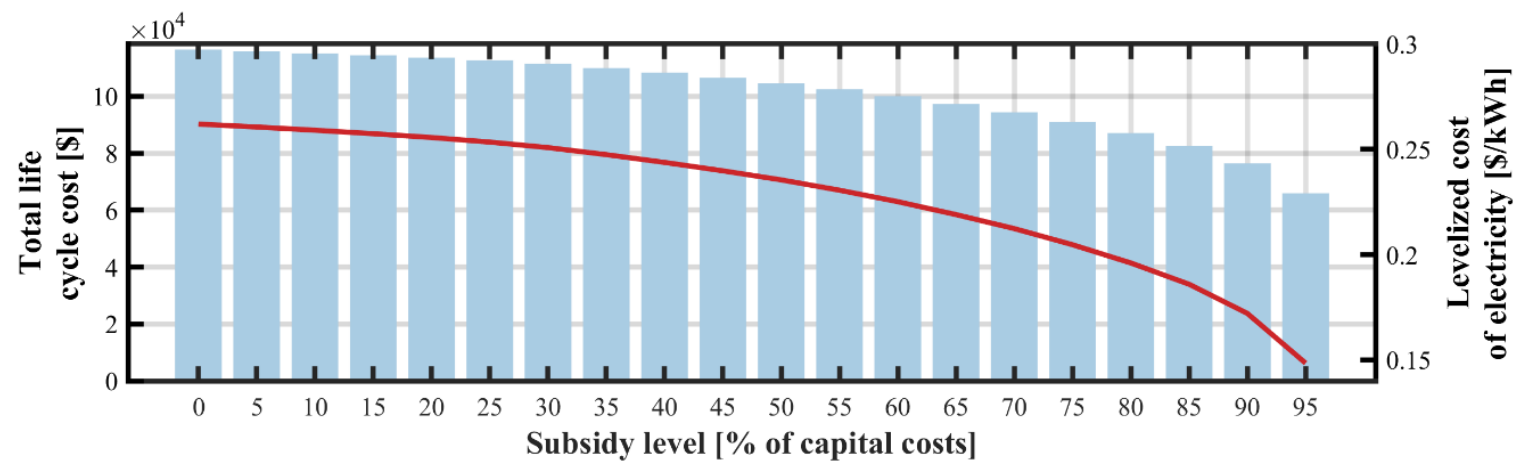

Figure 15. Simulation results of capital subsidies for wind technologies. Impact on LCOE and TLCC.

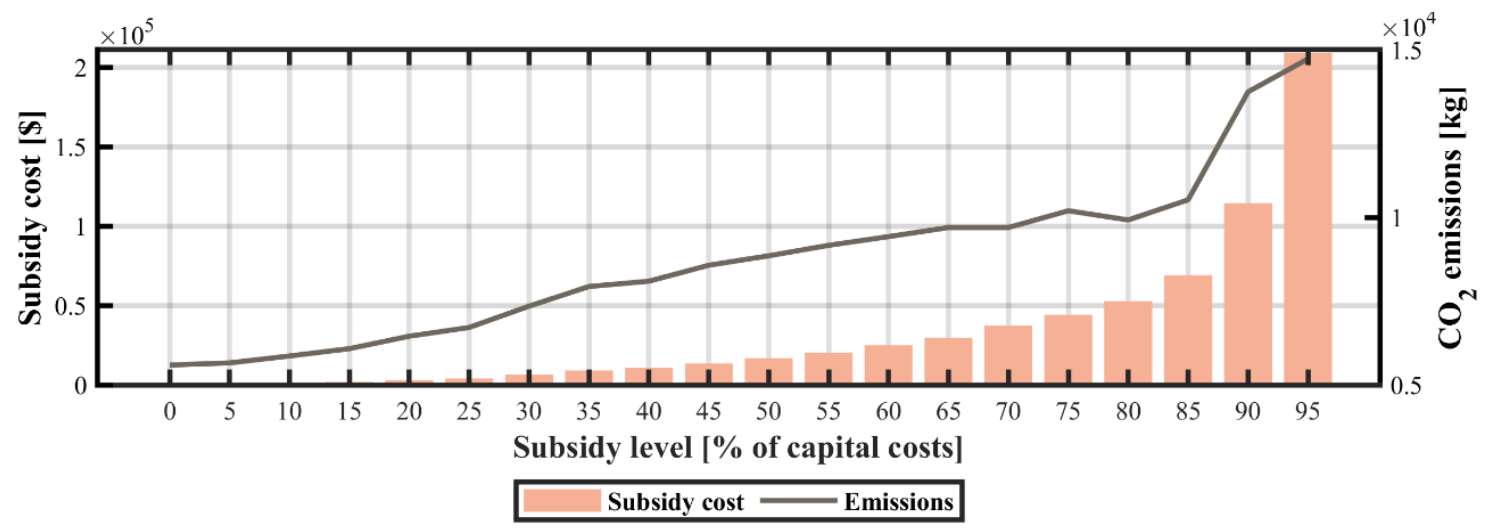

Figure 16. Simulation results of capital subsidies for wind technologies. Impact on subsidy costs and $\mathrm{CO}_{2}$ emission levels.

\subsection{Diesel Fuel Subsidies}

The unprecedented uncertainty on the global gas and oil markets as well as the volatility of fuel prices have a significant effect on the economics of microgrid systems. Moreover, fossil fuel subsidies provided by numerous governments have kept renewables at an economic disadvantage. According to the International Monetary Fund (IMF), emerging economies in Asia, Middle East, Latin America, and Sub-Sahara Africa continue to subsidize fossil fuels and account for almost $56 \%$ of the global energy subsidies [67]. These types of subsidies have intensified the barriers to the deployment of RES. Consequently, it is imperative to assess the impact of such subsidies on the final microgrid configuration, TLCC, LCOE, and $\mathrm{CO}_{2}$ emissions. The results obtained from the sensitivity analysis of diesel fuel subsidies are depicted in Figures 17-19. From the figures, it can be found that as the diesel price gradually decreases, the installed capacity of PV, wind, and battery technologies also decrease. With a higher subsidy level, RES become economically unviable and the entire system is mainly powered by a $16.5 \mathrm{~kW}$ diesel generator. Low diesel prices reduce the importance of renewable technologies and promote the utilization of diesel fuel for electricity generation. Further, out of all the subsidies analyzed in this study, fuel subsidies lead to the highest levels of carbon dioxide emissions and the lowest values of subsidy costs. Subsidies higher than $70 \%$ result in a sharp increase in the capacity of the diesel generator and in the second-lowest LCOE $(\$ 0.07 / \mathrm{kWh})$ observed among all analyzed cases. This also demonstrates that low capital costs of internal combustion engines combined with diesel fuel subsidies have a negative impact on the deployment of sustainable energy systems and on the reduction of greenhouse emissions. 


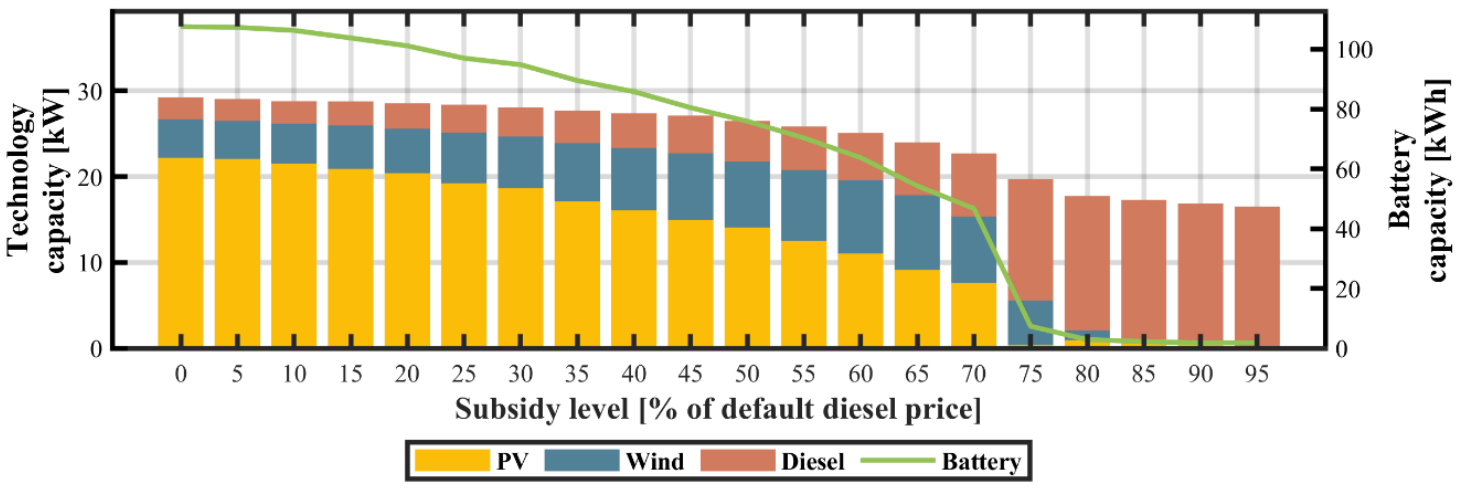

Figure 17. Simulation results of diesel fuel subsidies. Impact on the capacity of DG technologies.

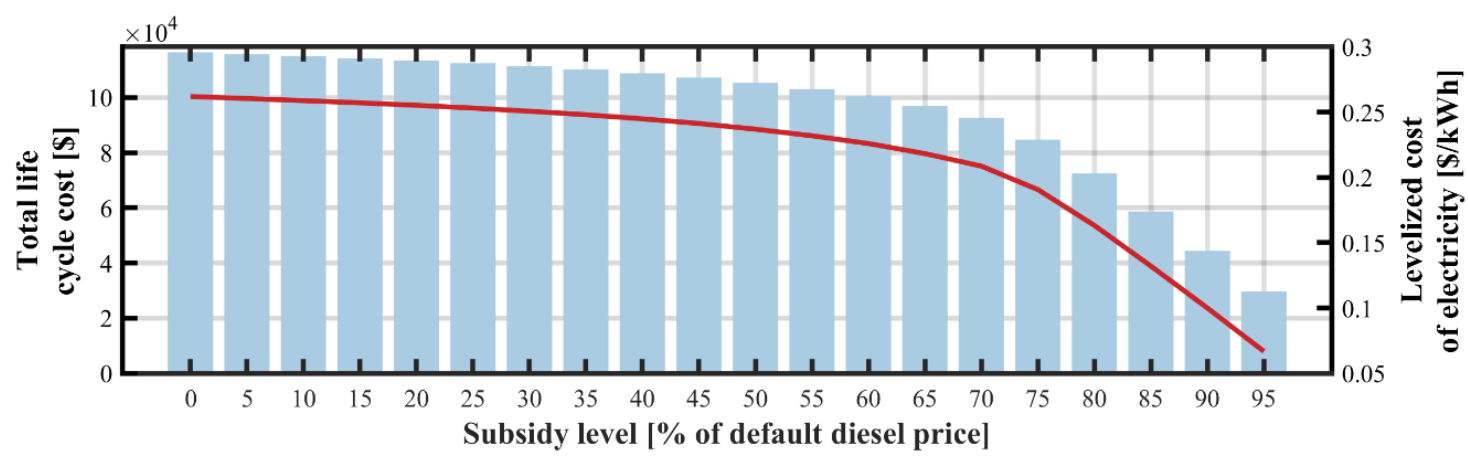

TLCC - LCOE

Figure 18. Simulation results of diesel fuel subsidies. Impact on LCOE and TLCC.

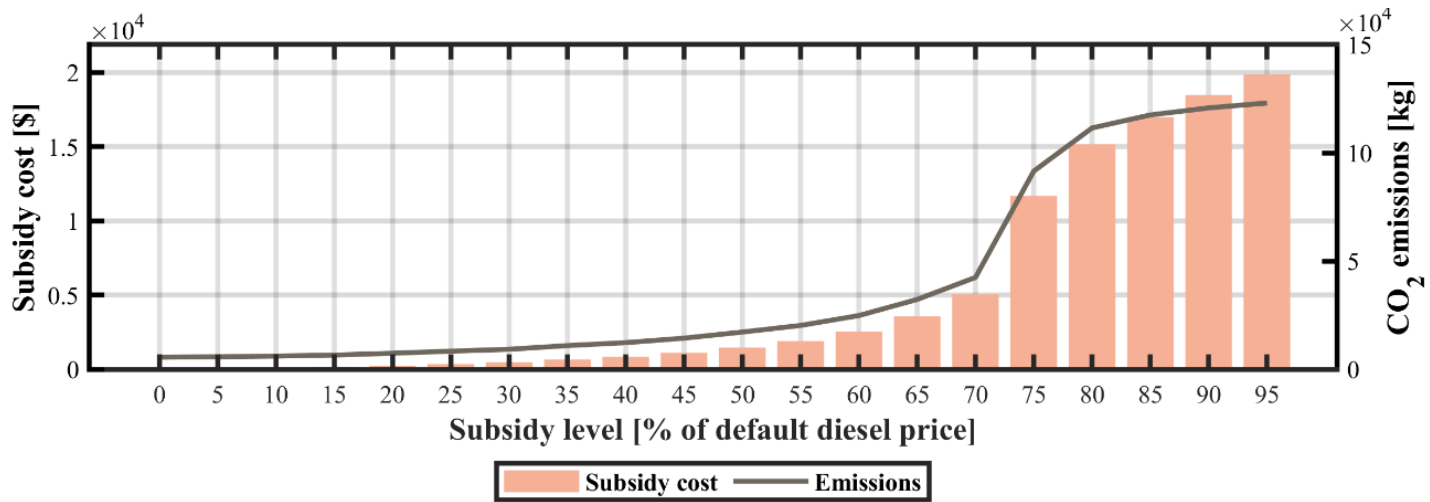

Figure 19. Simulation results of diesel fuel subsidies. Impact on subsidy costs and $\mathrm{CO}_{2}$ emission levels.

Figure 20 summarizes the simulation results of the five support interventions. It shows the change of the LCOE in microgrid systems as a function of the level of subsidy received. For the case where a capital subsidy is provided across all DG technologies and payable to reduce the upfront costs of the entire system, the change in the LCOE is linear (downward sloping since the capital cost of each component decreases at a similar rate). This type of subsidy results in the lowest and most predictable value of LCOE. For the cases where capital subsidies are available only to renewable technologies (PV and wind power), the drop in the LCOE is much more gradual. At a 50\% capital subsidy on renewable investments, the LCOE drops by approximately $20 \%$. As it can be observed from the figure, in our illustrative example PV technologies obtain a higher benefit from capital subsidies than wind technologies. Even though the same level of subsidy is available for both subsystems, due to limited wind potential at the selected site, a reduction in capital costs of wind technologies has a smaller impact 
on the LCOE. Only when capital subsidies are above $70 \%$ there is an observable difference between the LCOE of the two subsidy schemes. Similarly, for the case where diesel prices are subsidized, there is a steep drop in LCOE when the level of capital subsidies reaches $70 \%$. At this level of subsidization, the capacity of the diesel generator increases dramatically and displaces all other technologies in the system.

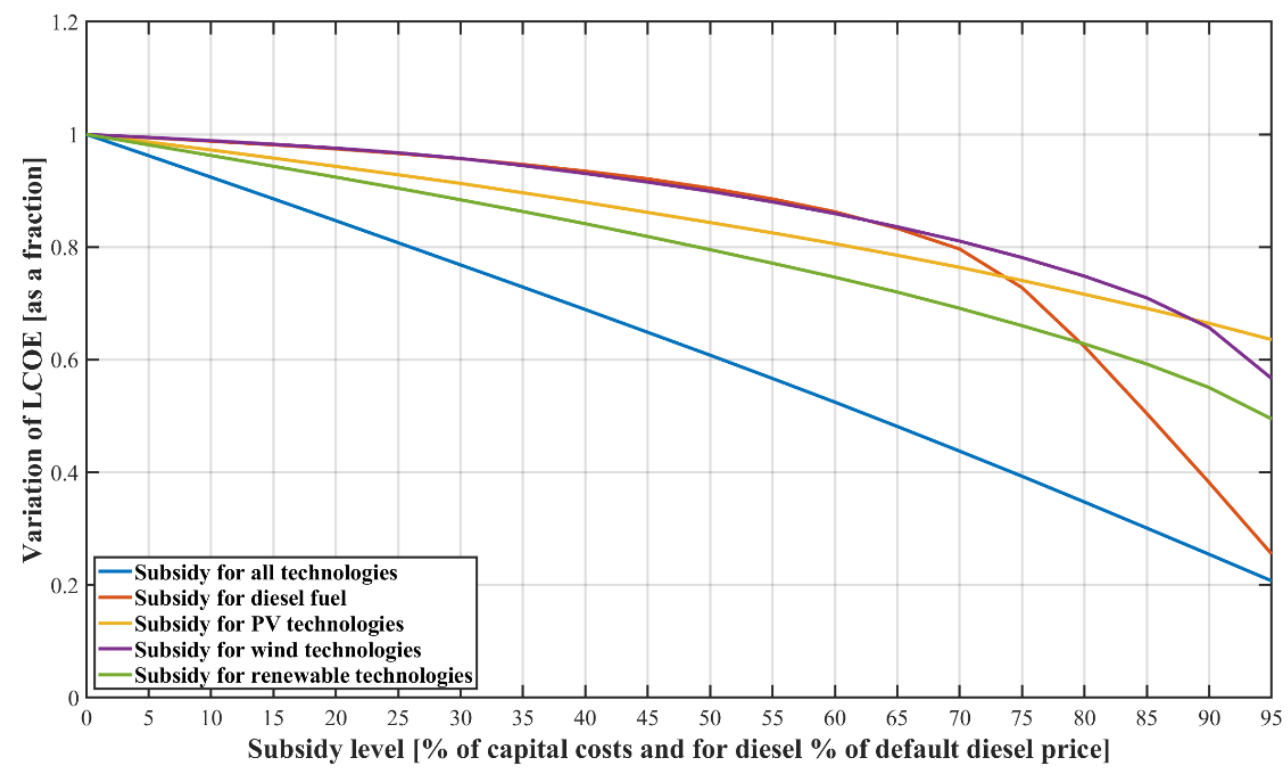

Figure 20. Impact of various policy instruments on the levelized cost of electricity.

\subsection{Interest Rate Sensitivity Analysis}

Figures 21-23 illustrate the effects of various interest rates on the optimal configuration of microgrids as well as their impact on the TLCC, LCOE, and total $\mathrm{CO}_{2}$ emissions. The range of the parameter associated with the interest rate was selected based on the analysis of lending rates in 107 developing economies. On the one hand, it can be observed that low interest rates favor capital-intensive technologies that have small O\&M costs (mainly PV and battery subsystems). On the other hand, high interest rates yield adverse environmental effects, increasing the total carbon dioxide emissions of the system. With higher interest rates, there is an increase on the utilization of diesel fuel and wind power for electricity generation, and a continuous drop in PV and battery capacities. As the objective function of the optimization model is defined in terms of TLCC and not LCOE, increasing interest rates lead to greater fuel consumption and higher LCOE values, exceeding $\$ 0.45 / \mathrm{kWh}$ with an $18 \%$ interest rate.

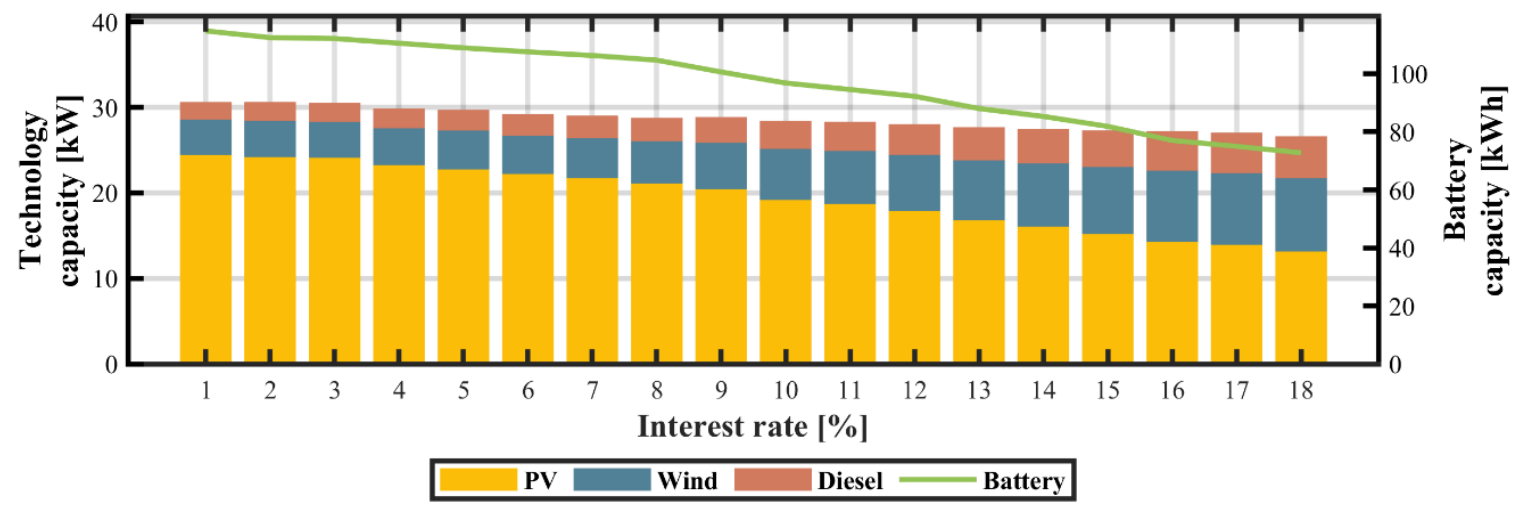

Figure 21. Simulation results of interest rate variation. Impact on the capacity of DG technologies. 


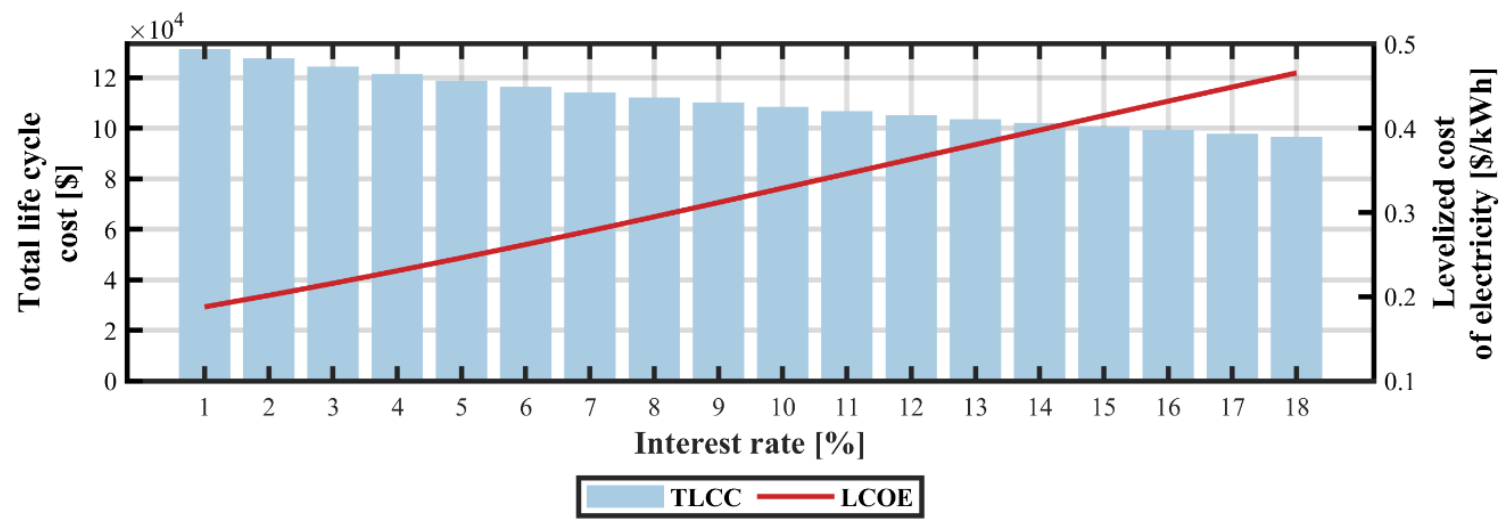

Figure 22. Simulation results of interest rate variation. Impact on LCOE and TLCC.

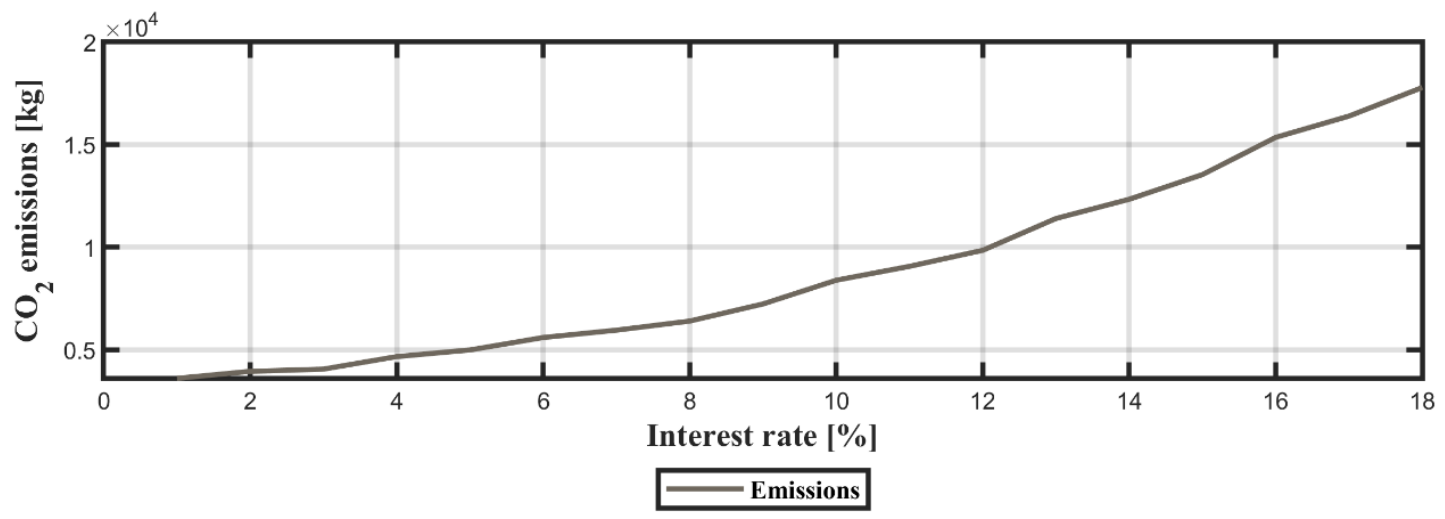

Figure 23. Simulation results of interest rate variation. Impact on $\mathrm{CO}_{2}$ emissions.

\subsection{Subsidies for PV and Electrical Energy Storage Technologies with Variation in Meteorological Parameters}

Solar and wind power generation are highly dependent on the local meteorological conditions. As a result, the sizing of these two components in a microgrid system is strongly related to the observed values of wind speed and solar irradiation. Currently, only a limited number of countries have proposed the use of financial incentives for batteries in small residential applications; therefore, it is of interest to understand the effects a hypothetical financial scheme for off-grid systems. Table 3 presents the results from the sensitivity analysis carried out to assess the impact of solar irradiation and wind speed on the LCOE of a system benefitting from a 50\% capital subsidy scheme (targeted towards PV and EES technologies). The sensitivity analysis showed that the system configuration with the lowest TLCC $(\$ 58,978)$ occurs at a wind speed of $7 \mathrm{~m} / \mathrm{s}$ and solar irradiation of $6 \mathrm{kWh} / \mathrm{m}^{2} /$ day. The majority of the electricity load is served by the PV $(20.52 \mathrm{~kW})$ and energy storage subsystems $(107.42 \mathrm{kWh})$ and backed up by a diesel generator $(2.51 \mathrm{~kW})$. At a wind speed of $3-4 \mathrm{~m} / \mathrm{s}$, the wind subsystem is fully excluded from the optimal configuration. Additionally, the analysis demonstrated that poor weather conditions ( $3 \mathrm{~m} / \mathrm{s}$ and $2 \mathrm{kWh} / \mathrm{m}^{2} /$ day) have a significant impact on the TLCC and consequently lead to a higher LCOE $(\$ 0.51 / \mathrm{kWh})$. This is due to the large EES $(140.68 \mathrm{kWh})$ and PV capacities $(73.91 \mathrm{~kW})$. Figure 24 shows the impact of the variation of meteorological parameters on the levelized cost of electricity. 
Table 3. Sensitivity analysis results for a PV and EES subsidy scheme with different meteorological conditions.

\begin{tabular}{|c|c|c|c|c|c|c|}
\hline \multicolumn{2}{|c|}{ Case } & \multicolumn{4}{|c|}{ Technology Capacity } & \multirow{2}{*}{$\operatorname{TLCC}(\$)$} \\
\hline $\begin{array}{l}\text { Wind Speed } \\
(\mathrm{m} / \mathrm{s})\end{array}$ & $\begin{array}{c}\text { Irradiation } \\
\left(\mathrm{kWh} / \mathrm{m}^{2} / \text { day }\right)\end{array}$ & Diesel (kW) & PV (kW) & Wind $(\mathrm{kW})$ & Battery (kWh) & \\
\hline 3 & 2 & 1.45 & 73.91 & 0.00 & 140.68 & 100,807 \\
\hline 3 & 3 & 1.32 & 51.39 & 0.00 & 142.39 & 83,128 \\
\hline 3 & 4 & 1.30 & 41.02 & 0.00 & 139.08 & 73,841 \\
\hline 3 & 5 & 1.23 & 34.19 & 0.00 & 138.77 & 67,928 \\
\hline 3 & 6 & 1.15 & 29.50 & 0.00 & 139.76 & 63,879 \\
\hline 4 & 2 & 1.29 & 65.24 & 3.09 & 130.82 & 99,630 \\
\hline 4 & 3 & 1.32 & 51.39 & 0.00 & 142.39 & 83,128 \\
\hline 4 & 4 & 1.30 & 41.02 & 0.00 & 139.08 & 73,841 \\
\hline 4 & 5 & 1.23 & 34.19 & 0.00 & 138.77 & 67,928 \\
\hline 4 & 6 & 1.15 & 29.50 & 0.00 & 139.76 & 63,879 \\
\hline 5 & 2 & 2.21 & 50.08 & 5.38 & 113.74 & 93,000 \\
\hline 5 & 3 & 1.51 & 41.54 & 3.25 & 124.29 & 79,998 \\
\hline 5 & 4 & 1.17 & 34.42 & 2.62 & 129.42 & 72,333 \\
\hline 5 & 5 & 0.97 & 30.39 & 1.78 & 132.29 & 67,299 \\
\hline 5 & 6 & 1.11 & 26.58 & 1.71 & 129.71 & 63,655 \\
\hline 6 & 2 & 4.68 & 30.32 & 8.70 & 76.40 & 84,692 \\
\hline 6 & 3 & 2.83 & 32.84 & 5.44 & 103.76 & 75,231 \\
\hline 6 & 4 & 2.24 & 29.14 & 4.24 & 112.41 & 68,958 \\
\hline 6 & 5 & 1.87 & 24.99 & 3.48 & 118.26 & 64,683 \\
\hline 6 & 6 & 1.80 & 22.61 & 3.05 & 119.14 & 61,599 \\
\hline 7 & 2 & 5.85 & 14.53 & 10.14 & 57.70 & 75,678 \\
\hline 7 & 3 & 4.34 & 23.47 & 6.91 & 80.22 & 70,114 \\
\hline 7 & 4 & 3.18 & 23.69 & 4.87 & 97.68 & 65,282 \\
\hline 7 & 5 & 2.70 & 22.09 & 4.07 & 104.75 & 61,619 \\
\hline 7 & 6 & 2.51 & 20.52 & 3.62 & 107.42 & 58,978 \\
\hline
\end{tabular}

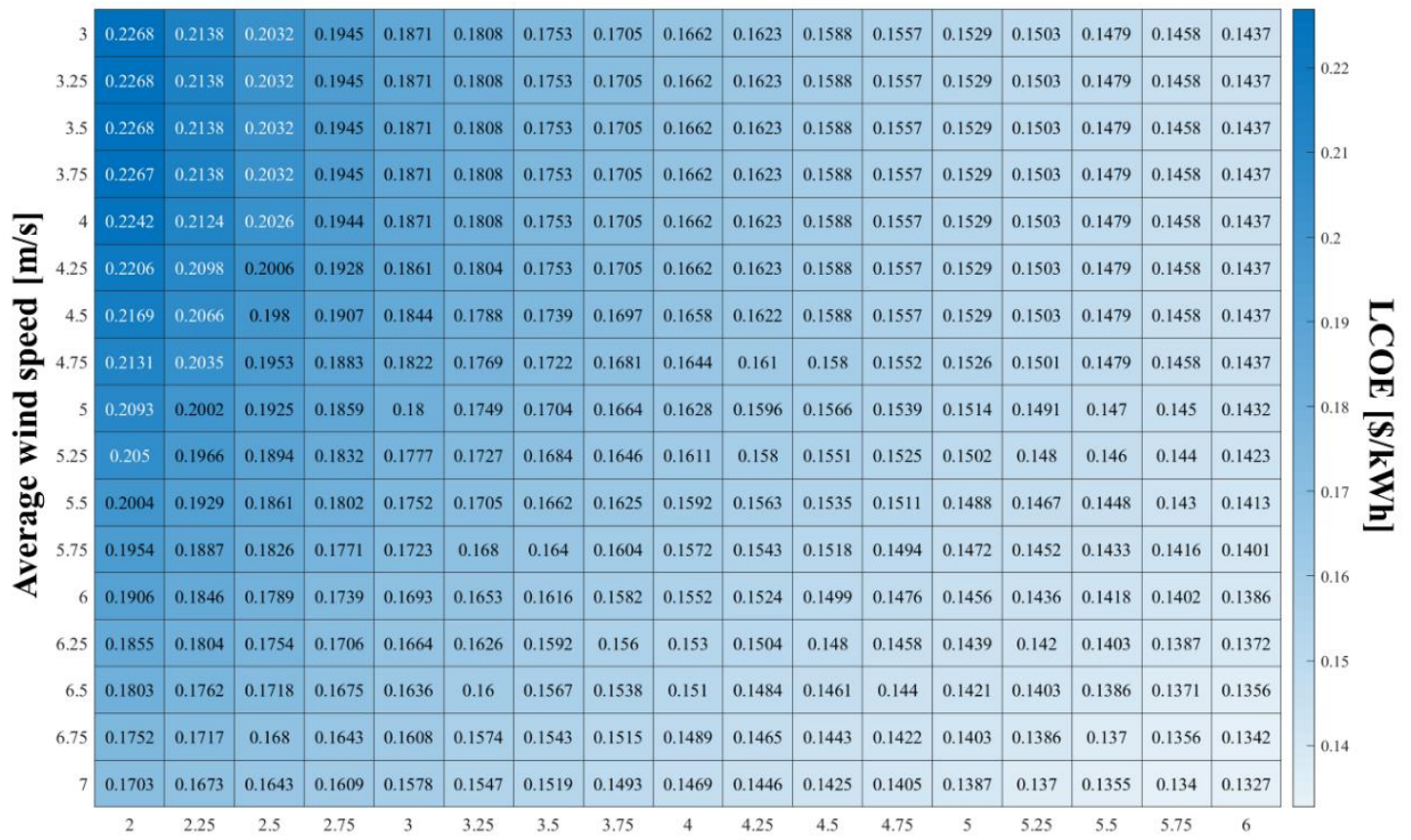

Average daily irradiation $[\mathrm{kWh} / \mathrm{m} 2 / \mathrm{day}]$

Figure 24. Sensitivity analysis of meteorological parameters. 


\section{Conclusions}

Microgrids with renewable energy sources and energy storage systems constitute one of the most promising solutions to meet the electrification targets of the United Nations Sustainable Development Goals. These types of power systems face significant barriers including high upfront costs and low technological readiness, which have prevented their dissemination in developing countries. Thus, there is a need for appropriate government support mechanisms that will help reduce investment risk and boost their deployment.

This paper evaluates the effects of financial incentives and subsidy policies on the optimal design and operation of a microgrid for rural electrification (systems disconnected to the main grid). A decision support tool based on a linear programming approach is employed to simulate the effect of various support mechanisms (e.g., capital and energy subsidies) and estimate their impact on the LCOE and optimal capacity of the microgrid systems. This study considers the illustrative example of a village of 90 households located in a subtropical region. The selected site was characterized by an average daily solar irradiation of $5.75 \mathrm{kWh} / \mathrm{m}^{2} /$ day and an average wind speed of $4.19 \mathrm{~m} / \mathrm{s}$.

Five different governmental interventions were evaluated: capital subsidies across all DG technologies, capital subsidies for renewable technologies, capital subsidies for PV technologies, capital subsidies for wind technologies, and diesel fuel subsidies. The simulation results show that capital subsidies across all DG technologies above $30 \%$ can lead to LCOEs below $\$ 0.2 / \mathrm{kWh}$, making microgrids more likely to be deployed. Financial incentives for renewable energy technologies result in a decrease in TLCC and LCOE; however, subsidies targeted to PV systems have a much greater impact on the microgrid architecture than subsidies for wind turbines. Moreover, the results from the optimization procedure demonstrate that there is a strong relationship between photovoltaic and battery storage capacities. Wind turbine capacities are strongly linked to the capacity of the backup diesel generator. This close interaction is also shown in the rise of emissions levels with the progressive increase in subsidies for wind technologies. Diesel subsidies have a negative impact on the deployment of renewable energy technologies, although this subsidy scheme results in the lowest levels of subsidy costs. The low upfront costs of internal combustion engines combined with fossil fuel subsidies hamper the expansion of renewables into microgrid systems.

The most apparent limitations of our study are as follows. First, distribution network losses as well as their cost implications are regarded as negligible. Additionally, the meteorological, economic, and technical parameters employed in the analysis are treated as statistic or fixed values during the lifetime of the project. Similarly, efficiencies and degradation rates are assumed to be constant, mainly due to the modeling approach employed for this study. Hence, to overcome these limitations and investigate their effects on the optimal configuration of microgrids, one important goal for future research is the introduction of these elements in the decision-support tool. Furthermore, another promising area in the investigation of microgrids and mini-grids is the evaluation of demand site management measures on projects with subsidy schemes frequently employed by governments and other institutions to promote rural electrification.

Finally, this study demonstrates the importance of tailoring financial support mechanisms for off-grid electrification to the local requirements, either at the regional or the national level. Several countries have developed a number of dedicated policies to stimulate investment and innovation in microgrids; however, in underdeveloped markets, the microgrid financial mechanisms remain undefined or uncertain, which has limited the number of worldwide installations.

Author Contributions: Conceptualization, P.B., A.S., J.K.; Data curation, P.B. and A.S.; Methodology, P.B., A.S. and J.K.; Software, P.B. and A.S.; Validation, P.B. and J.K.; Writing-original draft preparation, P.B. and A.S.; writing-review and editing, P.B. and J.K.; Visualization, P.B. and A.S.; Supervision, J.K. All authors have read and agreed to the published version of the manuscript.

Funding: This research received no external funding.

Acknowledgments: This work was carried out as part of the statutory activity of the Mineral and Energy Economy Research Institute of the Polish Academy of Sciences. 
Conflicts of Interest: The authors declare no conflict of interest.

\section{References}

1. Gujba, H.; Thorne, S.; Mulugetta, Y.; Rai, K.; Sokona, Y. Financing low carbon energy access in Africa. Energy Policy 2012, 47, 71-78. [CrossRef]

2. Corfee-Morlot, J.; Parks, P.; Ogunleye, J.; Ayeni, F. Achieving Clean Energy Access in Sub-Saharan Africa; Organisation for Economic Co-Operation and Development: Paris, France, 2019.

3. IEA; IRENA; UNSD; World Bank. WHO Tracking SDG7: The Energy Progress Report 2019; World Bank Group: Washington, DC, USA, 2019.

4. International Energy Agency. Energy Access Outlook 2017: From Poverty to Prosperity; International Energy Agency: Paris, France, 2017.

5. Ali, A.; Li, W.; Hussain, R.; He, X.; Williams, B.W.; Memon, A.H. Overview of Current Microgrid Policies, Incentives and Barriers in the European Union, United States and China. Sustainability 2017, 9, 1146. [CrossRef]

6. Hanna, R.; Ghonima, M.; Kleissl, J.; Tynan, G.; Victor, D.G. Evaluating business models for microgrids: Interactions of technology and policy. Energy Policy 2017, 103, 47-61. [CrossRef]

7. Hirsch, A.; Parag, Y.; Guerrero, J.M. Microgrids: A review of technologies, key drivers, and outstanding issues. Renew. Sustain. Energy Rev. 2018, 90, 402-411. [CrossRef]

8. United Nations. The Sustainable Development Goals Report 2019; United Nations: New York, NY, USA, 2019.

9. UNFCCC. Conference of the Parties (COP) Adoption of the Paris Agreement. In Proceedings of the Conference of the Parties COP 21, Adopt, Paris Agreement, Propos, Paris, France, 12 December 2015.

10. European Commission. 2030 Climate E Energy Framework; European Commission: Brussels, Belgium, 2014.

11. Barnes, D.F. Effective solutions for rural electrification in developing countries: Lessons from successful programs. Curr. Opin. Environ. Sustain. 2011, 3, 260-264. [CrossRef]

12. Adefarati, T.; Bansal, R. Reliability, economic and environmental analysis of a microgrid system in the presence of renewable energy resources. Appl. Energy 2019, 236, 1089-1114. [CrossRef]

13. IRENA. Innovation Outlook: Renewable Mini-Grids; IRENA: Abu Dhabi, United Arab Emirates, 2016.

14. Long, Y.; Pan, C.; Wang, Y. Research on a Microgrid Subsidy Strategy Based on Operational Efficiency of the Industry Chain. Sustainability 2018, 10, 1519. [CrossRef]

15. Williams, N.J. Microgrid Utilities for Rural Electrification in East Africa Challenges and Opportunities; Carnegie Mellon University: Pittsburgh, PA, USA, 2017.

16. The World Bank. World Bank Projects: Nigeria Electrification Project; The World Bank: Washington, DC, USA, 2018.

17. Operating Guidelines: Result Based Financing for Renewable Energy Investments in Green Mini and Micro Grids; Rural Energy Agency: Dodoma, Tanzania, 2016.

18. Singh, T. Energy MNRE Central Financial Assistance (CFA) for "Off-grid and Decentralized Solar Applications Programme" for the Year 2014-15; Technical Report; Government of India, Ministry of New \& Renewable Energy: New Dehli, India, 2014.

19. Microgrid Investment Accelerator Microgrid Market Analysis \& Investment Opportunities in India, Indonesia, and Tanzania; Microgrid Investment Accelerator: Oakland, CA, USA, 2017.

20. Imanto, P. Indonesia Sustainable Leastcost Electrification (ISLE); The World Bank: Washington, DC, USA, 2019.

21. Sarraf, M.; Rismanchi, B.; Saidur, R.; Ping, H.; Rahim, N. Renewable energy policies for sustainable development in Cambodia. Renew. Sustain. Energy Rev. 2013, 22, 223-229. [CrossRef]

22. Oung, W. Rural Electrification Fund Cambodia Providing Grants E Promoting Rural Electrification and Renewable Energy Technology; Rural Electrification Fund: Phnom Penh, Cambodia, 2008.

23. Ismail, M.; Moghavvemi, M.; Mahlia, T.M.I. Genetic algorithm based optimization on modeling and design of hybrid renewable energy systems. Energy Convers. Manag. 2014, 85, 120-130. [CrossRef]

24. Chedid, R.; Saliba, Y. Optimization and control of autonomous renewable energy systems. Int. J. Energy Res. 1996, 20, 609-624. [CrossRef]

25. Silvente, J.; Papageorgiou, L.G. An MILP formulation for the optimal management of microgrids with task interruptions. Appl. Energy 2017, 206, 1131-1146. [CrossRef] 
26. Lauinger, D.; Caliandro, P.; Van Herle, J.; Kuhn, D. A linear programming approach to the optimization of residential energy systems. J. Energy Storage 2016, 7, 24-37. [CrossRef]

27. Yang, H.; Zhou, W.; Lu, L.; Fang, Z. Optimal sizing method for stand-alone hybrid solar-wind system with LPSP technology by using genetic algorithm. Sol. Energy 2008, 82, 354-367. [CrossRef]

28. Anoune, K.; Bouya, M.; Astito, A.; Abdellah, A. Ben Sizing methods and optimization techniques for PV-wind based hybrid renewable energy system: A review. Renew. Sustain. Energy Rev. 2018, 93, 652-673. [CrossRef]

29. Siddaiah, R.; Saini, R. A review on planning, configurations, modeling and optimization techniques of hybrid renewable energy systems for off grid applications. Renew. Sustain. Energy Rev. 2016, 58, 376-396. [CrossRef]

30. Sinha, S.; Chandel, S. Review of software tools for hybrid renewable energy systems. Renew. Sustain. Energy Rev. 2014, 32, 192-205. [CrossRef]

31. Chen, W.; Zeng, Y.; Xu, C. Energy storage subsidy estimation for microgrid: A real option game-theoretic approach. Appl. Energy 2019, 239, 373-382. [CrossRef]

32. Long, Y.; Wang, Y.; Pan, C. Incentive Mechanism of Micro-grid Project Development. Sustainability 2018, 10, 163. [CrossRef]

33. Husein, M.; Chung, I.-Y. Optimal design and financial feasibility of a university campus microgrid considering renewable energy incentives. Appl. Energy 2018, 225, 273-289. [CrossRef]

34. Hau, V.B.; Husein, M.; Chung, I.-Y.; Won, D.; Torre, W.; Nguyen, T. Analyzing the Impact of Renewable Energy Incentives and Parameter Uncertainties on Financial Feasibility of a Campus Microgrid. Energies 2018, 11, 2446. [CrossRef]

35. Hassan, A.S.; Cipcigan, L.; Jenkins, N. Optimal battery storage operation for PV systems with tariff incentives. Appl. Energy 2017, 203, 422-441. [CrossRef]

36. Haghi, E.; Raahemifar, K.; Fowler, M. Investigating the effect of renewable energy incentives and hydrogen storage on advantages of stakeholders in a microgrid. Energy Policy 2018, 113, 206-222. [CrossRef]

37. Konstantinopoulos, S.A.; Anastasiadis, A.G.; Vokas, G.A.; Kondylis, G.; Polyzakis, A. Optimal management of hydrogen storage in stochastic smart microgrid operation. Int. J. Hydrog. Energy 2018, 43, 490-499. [CrossRef]

38. Chen, W.; Wei, P. Socially optimal deployment strategy and incentive policy for solar photovoltaic community microgrid: A case of China. Energy Policy 2018, 116, 86-94. [CrossRef]

39. Williams, N.J.; Jaramillo, P.; Taneja, J.; Ustun, T.S. Enabling private sector investment in microgrid-based rural electrification in developing countries: A review. Renew. Sustain. Energy Rev. 2015, 52, 1268-1281. [CrossRef]

40. Feng, W.; Jin, M.; Liu, X.; Bao, Y.; Marnay, C.; Yao, C.; Yu, J. A review of microgrid development in the United States-A decade of progress on policies, demonstrations, controls, and software tools. Appl. Energy 2018, 228, 1656-1668. [CrossRef]

41. Qu, M.; Marnay, C.; Zhou, N. Microgrid Policy Review of Selected Major Countries, Regions, and Organizations. Microgrid Policy Rev. Sel. Major Ctries. Reg. Organ. 2011. [CrossRef]

42. Milis, K.; Peremans, H.; Van Passel, S. The impact of policy on microgrid economics: A review. Renew. Sustain. Energy Rev. 2018, 81, 3111-3119. [CrossRef]

43. Hoke, A.; Brissette, A.; Chandler, S.; Pratt, A.; Maksimovizc, D. Look-ahead economic dispatch of microgrids with energy storage, using linear programming. In Proceedings of the 2013 1st IEEE Conference on Technologies for Sustainability (SusTech), Portland, OR, USA, 1-2 August 2013; pp. 154-161.

44. World Bank Energy. Available online: https://www.worldbank.org/en/topic/energy/overview (accessed on 3 January 2020).

45. IRENA. REthinking Energy 2017: Accelerating the Global Energy Transformation; IRENA: Abu Dhabi, United Arab Emirates, 2017; ISBN 9789295111059.

46. Oakleaf, J.; Kennedy, C.M.; Baruch-Mordo, S.; Gerber, J.; West, P.; Johnson, J.A.; Kiesecker, J. Mapping global development potential for renewable energy, fossil fuels, mining and agriculture sectors. Sci. Data 2019, 6, 101. [CrossRef]

47. Kojima, M. Fossil Fuel Subsidy and Pricing Policies: Recent Developing Country Experience; The World Bank: Washington, DC, USA, 2016.

48. Sengupta, M.; Xie, Y.; Lopez, A.; Habte, A.; Maclaurin, G.; Shelby, J. The National Solar Radiation Data Base (NSRDB). Renew. Sustain. Energy Rev. 2018, 89, 51-60. [CrossRef]

49. Mandelli, S.; Merlo, M.; Colombo, E. Novel procedure to formulate load profiles for off-grid rural areas. Energy Sustain. Dev. 2016, 31, 130-142. [CrossRef] 
50. Mandelli, S. Strategies for Acces to Energy in Developing Countries-Methodes and Models for Off-Grid Power System Design; Politecnico di Milano: Milano, Italy, 2014.

51. Porras, J. Estudio De Soluciones Para Integración De Microproducciones En Redes Aisladas, Instituto Politecnico De Leira; Escola Superior de Tecnologia e Gestão: Leiria, Portugal, 2017.

52. Kasaeian, A.; Rahdan, P.; Rad, M.A.V.; Yan, W.-M. Optimal design and technical analysis of a grid-connected hybrid photovoltaic/diesel/biogas under different economic conditions: A case study. Energy Convers. Manag. 2019, 198. [CrossRef]

53. Walker, A. PV O\&M Cost Model and Cost Reduction; National Renewable Energy Laboratory: Lakewood, CO, USA, 2017.

54. Sarkar, T.; Bhattacharjee, A.; Samanta, H.; Bhattacharya, K.; Saha, H. Optimal design and implementation of solar PV-wind-biogas-VRFB storage integrated smart hybrid microgrid for ensuring zero loss of power supply probability. Energy Convers. Manag. 2019, 191, 102-118. [CrossRef]

55. Predescu, M. Economic evaluation of small wind turbines and hybrid systems for residential use. Renew. Energy Environ. Sustain. 2016, 1, 33. [CrossRef]

56. Huneke, F.; Henkel, J.; González, J.A.B.; Erdmann, G. Optimisation of hybrid off-grid energy systems by linear programming. Energy Sustain. Soc. 2012, 2, 7. [CrossRef]

57. Anuphappharadorn, S.; Sukchai, S.; Sirisamphanwong, C.; Ketjoy, N. Comparison the Economic Analysis of the Battery between Lithium-ion and Lead-acid in PV Stand-alone Application. Energy Procedia 2014, 56, 352-358. [CrossRef]

58. IRENA. Electricity Storage and Renewables: Costs and Markets to 2030; IRENA: Abu Dhabi, United Arab Emirates, 2017.

59. Trading Economics Interest Rate. Available online: https://radingeconomics.com/country-list/interest-rate (accessed on 28 November 2019).

60. Homer Energy HOMER-Hybrid Renewable and Distributed Generation System Design Software. Available online: http://www.homerenergy.com (accessed on 14 January 2020).

61. Hafez, O.; Bhattacharya, K. Optimal planning and design of a renewable energy based supply system for microgrids. Renew. Energy 2012, 45, 7-15. [CrossRef]

62. Oulis-Rousis, A.; Tzelepis, D.; Konstantelos, I.; Booth, C.; Strbac, G. Design of a Hybrid AC/DC Microgrid Using HOMER Pro: Case Study on an Islanded Residential Application. Inventions 2018, 3, 55. [CrossRef]

63. Schnitzer, D.; Deepa, S.; Carvalo, J.P.; Ranjit, D.; Jay, A.; Daniel, K. Microgrids for Rural Electrification: A Critical Review of Best Practices Based on Seven Case Studies; United Nations Found: New York, NY, USA, 2014.

64. IRENA. Renewable Power Generation Costs in 2017; IRENA: Abu Dhabi, United Arab Emirates, 2018; ISBN 978-92-9260-040-2.

65. Sharif, I.; Mithila, M. Rural Electrification using PV: The Success Story of Bangladesh. Energy Procedia 2013, 33, 343-354. [CrossRef]

66. Nygaard, I.; Bhamidipati, P.L.; Andersen, A.E.; Larsen, T.H.; Cronin, T.; Davis, D.N. Market for the Integration of Smaller Wind Turbines in Mini-Grids in Uganda; Kenya Miniwind: Aarhus, Denmark, 2018.

67. Coady, D.; Parry, I.; Le, N.-P.; Shang, B. Global Fossil Fuel Subsidies Remain Large: An Update Based on Country-Level Estimates; IMF: Washington, DC, USA, 2019.

(C) 2020 by the authors. Licensee MDPI, Basel, Switzerland. This article is an open access article distributed under the terms and conditions of the Creative Commons Attribution (CC BY) license (http://creativecommons.org/licenses/by/4.0/). 